\title{
Transcriptional and translational regulation of pathogenesis in Alzheimer's disease model mice
}

\author{
Guillermo Eastman ${ }^{\mathrm{a}, \mathrm{b}}$, Elizabeth R. Sharlow ${ }^{\mathrm{c}}$, John S. Lazo ${ }^{\mathrm{c}, \mathrm{d}}$, George S. Bloom ${ }^{\mathrm{b}, \mathrm{e}, \mathrm{f}}$ and José \\ R. Sotelo-Silveira ${ }^{a, g}$ *
}

aDepartamento de Genómica, Instituto de Investigaciones Biológicas Clemente Estable, Ministerio de Educación y Cultura, Montevideo, Uruguay

${ }^{b}$ Department of Biology, University of Virginia, Charlottesville, VA, USA

${ }^{c}$ Department of Pharmacology, University of Virginia, Charlottesville, VA, USA

${ }^{d}$ Department of Chemistry, University of Virginia, Charlottesville, VA, USA

${ }^{e}$ Department of Cell Biology, University of Virginia, Charlottesville, VA, USA

${ }^{f}$ Department of Neuroscience, University of Virginia, Charlottesville, VA, USA

'Sección Biología Celular, Facultad de Ciencias, Universidad de la República, Montevideo, Uruguay

* Correspondence to:

José R. Sotelo-Silveira, Departamento de Genómica, Instituto de Investigaciones Biológicas Clemente Estable, Av. Italia 3318, 11600, Montevideo, Uruguay. Tel.: +598 24871616 (173); Email: jsotelosilveira@iibce.edu.uy or sotelojos@gmail.com

George S. Bloom, Department of Biology, University of Virginia, PO Box 400328, Charlottesville, VA 22904-4328, USA. Tel.: +1 434243 3543; Email: gsb4g@virginia.edu

Running title: Tandem RNA-Seq \& Ribo-Seq of AD Mouse Models 


\section{ABSTRACT}

Background: Defining the cellular mechanisms that drive Alzheimer's disease (AD) pathogenesis and progression will be aided by studies defining how gene expression patterns change during pre-symptomatic AD and the ensuing periods of steadily declining cognition. Previous studies have emphasized changes in transcriptional regulation, but not translational regulation, leaving the ultimate results of gene expression alterations relatively unexplored in the context of AD.

Objective: To identify genes whose expression might be regulated at the transcriptional, and especially at the translational levels in $A D$, we analyzed gene expression in cerebral cortex of two AD model mouse strains, CVN (APP ${\text { SwDI; } N O S 2^{-/} \text {) and Tg2576 (APP }}_{\text {Sw }}$ ), and their companion wild type (WT) strains at 6 months of age by tandem RNA-Seq and Ribo-Seq (ribosome profiling).

Methods: Identical starting pools of bulk RNA were used for RNA-Seq and Ribo-Seq. Differential gene expression analysis was performed at the transcriptional and translational levels separately, and also at the translational efficiency level. Regulated genes were functionally evaluated by gene ontology tools.

Results: Compared to WT mice, AD model mice had similar levels of transcriptional regulation, but displayed differences in translational regulation. A specific microglial signature associated with early stages of $A \beta$ accumulation was up-regulated at both transcriptome and translatome levels in CVN mice. Although the two mice strains did not share many regulated genes, they showed common regulated pathways related to APP metabolism associated with neurotoxicity and neuroprotection.

Conclusion: This work represents the first genome-wide study of brain translational regulation in animal models of $A D$, and provides evidence of a tight and early translational regulation of gene expression controlling the balance between neuroprotective and neurodegenerative processes in brain.

Keywords: Alzheimer's disease, transcriptional regulation, RNA seq, mRNA translation, microglia, amyloid 


\section{INTRODUCTION}

Alzheimer's disease (AD) is a progressive brain neurodegenerative disorder and the most common cause of dementia. Individuals with $A D$ respond only marginally and briefly to currently available drugs and their long-term care is extremely costly. At the histopathological level, AD has well characterized hallmarks that include extracellular plaques made from amyloid-beta $(A \beta)$ peptides, intraneuronal tangles made from the microtubule-associated protein, tau, synapse loss and neuron death [1].

A comprehensive understanding of the molecular mechanisms underlying $A D$ is paramount for the development of novel therapies that can impede its onset and progression. In particular, impaired mRNA translation has been implicated in other neurological diseases [2-5], and there are reports linking $A \beta$ and tau to dysregulated translation [6-12]. For example, local protein synthesis is altered in brain synaptosomes isolated from an $A D$ mouse model that overproduces $A \beta[6]$ and $A \beta$ oligomers induce de novo synthesis of tau itself [8]. Also tau interacts with ribosomes in vitro [9] and in vivo, and decreases global translation [12] and the synthesis of ribosomal proteins [7]. Recently, an antisense transcript-mediated mechanism regulating tau translation has been described and implicated in human brain tau pathologies [13]. Furthermore, $A \beta$ and tau work coordinately to regulate the mTORC1 complex $[14,15]$, which controls a plethora of cellular functions, including mRNA translation [16].

A diversity of genomics tools have been developed to understand neurodegenerative diseases [17], resulting in powerful studies to explore transcriptional changes associated with $A D$ [18-21]. However, translational regulation has barely been examined, and other than one study about microglia [22], we are unaware of any work that directly compared transcriptional and translational regulation in the context of $A D$. Here, we describe the use of ribosome profiling, or Ribo-Seq [23-25], as a genomic screening technique to detect mRNA translation regulation in

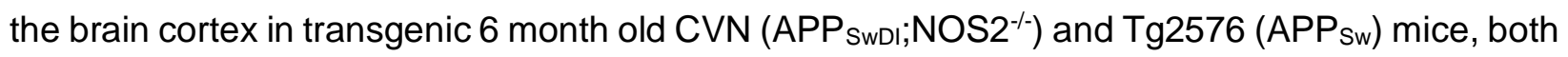
of which model human AD, and in wild type (WT) mice of the same strain backgrounds. At that age, CVN mice do not yet express any of the AD-like histological or behavioral phenotypes seen

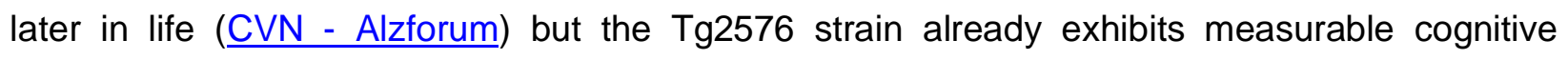
impairment, reduced (long-term potentiation) LTP in the dentate gyrus and limited neuron loss (Tg2576 - Alzforum)

Beginning with isolated, bulk cortical RNA, we performed RNA-Seq to define mRNA steady-state levels, and in tandem we produced and sequenced ribosome-associated mRNA 
footprints that revealed the exact positions of active ribosomes on mRNAs in the process of being translated into proteins. Quantitative analysis allowed us to estimate translational levels at a genome-wide level and to compare translational efficiency [24] between transgenic mice and their WT counterparts. We thereby uncovered translationally regulated genes with a complex signature that implicated genes involved in elevated $A \beta$ production and neurotoxicity as well as in reducing the $A \beta$ load in brain.

\section{MATERIALS AND METHODS}

Mice

Three 6 month old male mice from each of the following genotypes were used: CVN [26], Tg2576 [27] and their respective WT controls (C57/BL6 and B6;SJL, respectively; see Table 1). Animals were maintained, bred and euthanized in compliance with all policies of the Animal Care and Use Committee of the University of Virginia.

\section{Transcriptomic and ribosome profiling of brain cortex}

Cortices ( 250 mg each) were dissected from freshly removed brains in ice cold PBS containing $100 \mu \mathrm{g} / \mathrm{ml}$ cycloheximide (CHX; Sigma-Aldrich, catalog \# 01810). The tissue was then cut into smaller pieces with a sterile scalpel and Dounce homogenized on ice in lysis buffer (5 $\mathrm{mM}$ Tris $\mathrm{pH} 7.5,2.5 \mathrm{mM} \mathrm{MgCl}_{2}, 1.5 \mathrm{mM} \mathrm{KCl}, 0.5 \%$ Triton X-100, 0.5\% sodium deoxycholate, 2

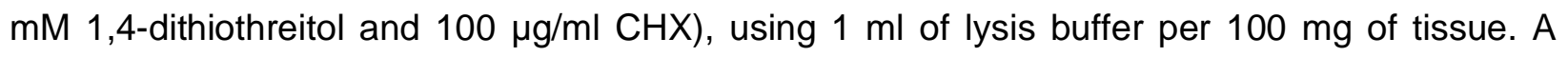
transcriptome sample was then separated and total RNA was isolated using a mirVana Total RNA Isolation Kit (Invitrogen, catalog \# AM1560) according to the vendor's recommended protocol.

Ribo-Seq was performed as previously described [28,29]. Briefly, lysate samples isolated as just described were centrifuged twice at $4^{\circ} \mathrm{C}$ at $\sim 17,000 \mathrm{~g}$, for 1 and 10 minutes consecutively, to remove large cellular debris, nuclei, and mitochondria. The post-mitochondrial supernatant $\left(\sim 1.6 \mathrm{ml} ; \mathrm{OD}_{260}=5-10 \mathrm{AU}\right)$ was loaded onto a $12-33.5 \%(\mathrm{w} / \mathrm{v})$ sucrose cushion prepared in polysome buffer (20 mM HEPES pH 7.5, $5 \mathrm{mM} \mathrm{MgCl}_{2}, 100 \mathrm{mM} \mathrm{KCl,} 100 \mu \mathrm{g} / \mathrm{ml} \mathrm{CHX)}$ and centrifuged for 2 hours at 36,000 rpm $\left(222,228 \mathrm{~g}_{\max }\right)$ in a Beckman SW41Ti rotor at $4^{\circ} \mathrm{C}$. The polysome-enriched pellet was resuspended in polysome buffer and digested with 180-200 units of Benzonase nuclease (Millipore, catalog \# E1014) for 10 minutes at room temperature to 
remove the RNA that was unprotected by ribosomes and thus produce protected ribosome footprints. Digestion was stopped by addition of 3 volumes of mirVana Lysis Buffer, and the RNA was isolated and then concentrated by overnight precipitation with $80 \%$ ethanol to maximize small RNA recovery. The concentrated RNA (10-15 $\mu \mathrm{g}$ per sample) was then size fractionated by electrophoresis using 15\% polyacrylamide-urea gels (ThermoFisher Scientific, catalog \# EC68852BOX) run at 200 volts in TBE (89 mM Tris-borate, $\mathrm{pH}$ 8.3, $2 \mathrm{mM}$ EDTA) for 65 min to separate ribosome-protected mRNA footprints. Gels were stained using GelRed (Biotium, catalog \# 41003) and circular agitation for 10 minutes in the dark. The ribosome footprint bands were identified using 26-mer and 34-mer RNA oligonucleotides [30], and excised in a dark room under UV light exposure. RNA recovery from gel slices was done overnight at room temperature by gentle mixing on a Nutator [30]. Size, quality and quantity of both transcriptome and translatome samples were evaluated in an Agilent 2100 Bioanalyzer using Nano and Small RNA kits (Agilent Technologies, catalog \#s 5067-1511 and 5067-1548, respectively).

\section{Sequencing}

All transcriptome and translatome samples were sequenced at BGI Tech Solutions (Hong Kong). Transcriptome samples were sequenced using an RNA-Seq quantification library protocol with ribosomal RNA (rRNA) removal library preparation, yielding at least 20 million paired-end (2x100 bp) reads. Translatome samples (ribosome footprints) were processed by small RNA library protocol, yielding at least 100 million single-end (50 bp) reads. Raw sequence data are available at the NCBI Sequence Read Archive (SRA; https://race.ncbi.nIm.nih.gov/Traces/sra/) under BioProject ID PRJNA677972.

\section{Data Analysis}

Quality control of sequence files was performed using FastQC [31] and then mapped against the Mus musculus genome (mm10/GRCm38 version) using bowtie2 [32] and defaults parameters. Read counts over mRNAs or genes were estimated by featureCounts [33], and differential gene expression analysis of transcriptomes or translatomes was done separately using edge $R$ [34], comparing each strain with its respective WT parental strain. Normalized counts were exported, and translational efficiency was calculated and contrasted between AD model mouse strains and their WT counterparts using the Xtail R package [35]. For all comparisons 
(transcriptome, translatome and translational efficiency) differentially expressed genes (DEGs) were defined by a false discovery rate (FDR) adjusted $p$-value $<0.05$ and a fold change of $>1$ or $>1.5$, as indicated in each case. Functional interpretation and ontology enrichment analysis of DEG lists were performed using Ingenuity Pathway Analysis (IPA; QIAGEN Inc.) [36], online tools like STRING [37] and g:Profiler [38], and in-house software (manuscript in preparation; https://github.com/sradiouy/ldMiner). AmiGO2 database [39] was used to retrieve genes related to $A P P, A \beta$ and tau. Plots were generated using $R$, by general or specific packages, such as pheatmap (https://CRAN.R-project.org/package=pheatmap) and GOplot [40].

\section{RESULTS}

High quality datasets of brain transcriptome and translatome differentiate CVN and Tg2576 models

CVN and Tg2576 AD model mice, and the parental WT strains from which they were derived (Table 1 and Fig. 1A) were used to explore transcriptional and translational gene expression regulation in the brain cortex of six month old animals using RNA-Seq and Ribo-Seq, respectively (Fig. 1B). More than 20 million paired-end reads were obtained for transcriptomes and an average of 120 million reads were acquired for translatomes (Table S1), derived from total RNA and isolated ribosome footprints (Fig. S1), respectively. In the transcriptome samples, $88 \%$ of the reads aligned over the reference genome, of which $90 \%$ mapped to gene regions and $77 \%$ to mRNA regions (Table S1). On the other hand, in the translatome samples we mapped more than 10 million reads over mRNAs (Table S1). In this case, ribosomal RNA depletion was avoided to minimize protocol biases.

Expression levels (CPM, counts per million) were estimated for more than 14 thousand different mRNAs in each sample above low/noise signal (Fig. S2). Inter-replicate correlations indicated high similarity within either transcriptome or translatome samples, but as expected, lower correlations were detected between RNA-Seq (transcriptome) and Ribo-Seq (translatome) data (Fig. S3). Quality control comparisons between transcriptome and translatome samples revealed the expected difference at the level of triplet periodicity and read distribution among mRNA features (Fig. S4 and S5). In addition, principal component analysis (PCA) showed a clear separation between genotypes for both RNA-Seq and Ribo-Seq datasets (Fig. S6). 
Gene expression is regulated transcriptionally and translationally in cortices of CVN and Tg2576 mice

We used the edge $R$ R package [34] to detect differences in cortical gene expression ( $p$ adjusted value $<0.05$ ) with a directionally independent fold change (FC) of $>1$ between the transgenic mice and their respective WT controls at both the transcriptional and translational levels. For CVN versus their WT parental strain (C57/BI6), we found 469 differentially expressed genes (DEGs) at the transcriptome level and 1165 DEGs at the translatome level. Of those, 240 and 377 genes had $>1.5$-fold differential expression by RNA-Seq and Ribo-Seq, respectively (Table 2 and Fig. 2). For Tg2576 versus their WT counterparts (B6;SJL), we found 343 DEGs at the transcriptome level and 135 at the translatome level with FC $>1$. Out of those totals, 140 transcriptionally regulated and 94 translationally regulated genes had a FC >1.5 (Table 2 and Fig. 3). Complete lists of the DEGs detected for CVN and Tg2576 mice are found in Tables S2 and S3, respectively.

To disentangle transcriptome from translatome regulation, we estimated translational efficiencies based on the ratios between translatome- and transcriptome-derived expressions levels for each transgenic strain and its WT parental counterpart. For this we used the Xtail R package [35], which revealed that CVN cortices contained 797 translationally regulated genes with FC $>1$, of which 144 had a FC $>1.5$ (Table 2 and Fig. 2). Similarly, Tg2576 cortices were found to contain 87 translationally regulated genes with $\mathrm{FC}>1$, of which 50 had a FC $>1.5$ (Table 2 and Fig. 3).

The global distribution of DEGs values, the relationship between FC and p-adjusted values, and the association between transcriptome and translatome FCs are shown for both $A D$ mouse models in Figures 2, 3, S7 and S8. As expected, DEGs were distributed along all expression levels (Fig. 2A and D, 3A and D) and the relationship between FC and p-adjusted values showed classic Volcano plots for both transcriptome and translational efficiency levels (Fig. 2B and $\mathrm{E}, 3 \mathrm{~B}$ and $\mathrm{E}$ ). When the $\mathrm{FC}$ at the translatome level was plotted against the transcriptome, a clear correlation was observed (Fig. 2C and 3C). For example, in CVN mice, 106 out of the 160 DEGs with a FC >1.5 at the transcriptome level were also DEGs at the same cutoff at the translatome level (Fig. S9). A similar correlation was evident for the transcriptionally downregulated genes; 32 out of 80 were also down-regulated at the translational level (Fig. S9). Analogous results were also observed in Tg2576 mice (Fig. S9), and indicated the expected association between transcriptome and translatome samples. 
By comparison, translationally regulated genes, although less in number than those regulated transcriptionally, showed a different pattern of regulation (Fig. 2F and 3F). In general, translational efficiency regulation involved genes with minimal changes at transcriptome levels (FC 1). This pattern was also apparent in the DEGs expression heatmap (Fig. 4). Transcriptome regulated genes expression levels showed classical patterns of regulation in contrast to the translational efficiency regulation. For example, similar expression levels for the transcriptome coupled with an increase or decrease for the translatome implied translational efficiency regulation. This scenario, among others, could be observed in the heatmaps of Figure 4. Heatmaps of regulated genes exclusively at the translational level are described in Figures S7D and S8D for CVN and Tg2576 mice, respectively. Collectively, these results demonstrate differential transcriptional and translational regulation of gene expression in both murine $A D$ models.

\section{Regulation of distinct biological pathways in cortices of CVN versus Tg2576 mice}

We next used Ingenuity Pathway Analysis (IPA) [36] to identify biological functions associated with genes that were up-regulated or down-regulated at FC >1 in CVN and Tg2576 mice compared to their respective WT counterparts. CVN mice showed a clear functional response at the transcriptome, translatome and translational efficiency levels (Fig. 5, S10 and Table S4). Down-regulated biological functions in CVN mice were dominated by processes indicative of neuronal decline, such as neurodegeneration, demyelination, and decreased axon growth, LTP and glutamate release. In contrast, indicators of myelination, glial cell abundance and neurotransmission were identified by IPA as major up-regulated processes in CVN mice. IPA also detected an up-regulated neuroprotective response for microglia, which may reflect the early accumulation of $A \beta$. However, IPA also detected activation of neurodegeneration-related processes like reduced axon growth and increased neuron death, especially at the transcriptional level (Table S4). Moreover, at the translational efficiency level, IPA reported a marginal (low zscore) decrease in LTP related genes (Fig. 5).

In contrast, only a few overrepresented functional categories in Tg2576 mice were identified with IPA (Fig. 5 and Table S4). At the transcriptome level no categories were found to decrease, and only three categories increased: neuritogenesis, microtubule dynamics and synaptic transmission. At the translatome level only the category of quantity of microglia was 
decreased, but with a low z-score, and no categories increased. No functional categories in translational efficiency were detected.

Using IPA again, we then performed an upstream analysis to infer modulated genes by the observed regulation of their targets. For CVN mice, most of the upstream genes were closely related to $A D$ pathology and implied protective reactions to avoid $A \beta$ accumulation and counter neurodegeneration (Fig. 6). For example, upstream genes that were suppressed included: PSEN1, PSEN2, APOE, B4GALNT1, ST8SIA1 and CTCF at the transcriptome level; SSB at the translatome level; and $A D O R A 2 A$ at the translational efficiency level. Decreased expression levels of PSEN1, PSEN2 and APOE could signal a defense response against $A \beta$ production, as might reduced expression of B4GALNT1 and ST8SIA1, ganglioside synthases that increase APP cleavage and affect memory [41,42]. CTCF encodes a transcription factor that can act as an activator or repressor, and also serves as an insulator protein that defines chromatin domains and can up-regulate APP expression [43]. CTCF knockout in mouse hippocampus increases cytokine expression and activates microglia [44]. ADORA2A is an adenosine receptor, and its pharmacological inhibition or downregulation restores LTP and reverses memory deficits $[45,46]$.

On the other hand, upstream genes indicated as activated seem to represent both protective and degenerative responses (Fig. 6). TCF7L2 and CSF1, which we found to be activated at the transcriptome level, probably have a protective function. TCF7L2 may be involved in improving neurogenesis and compensate neuron loss [47] and CSF1 has been linked to microglial activation, prevention of cognitive loss and reduction of $A \beta$ accumulation $[48,49]$. PTF1A and IFNG, identified as upstream activated genes at the translational level, may also be protective. PTF1A can induce neuronal stem cell generation and improve cognitive dysfunction [50]. IFNG, which encodes interferon gamma (IFN- $\gamma$ ), can activate microglia to suppress $A \beta$ deposition and induce neurogenesis [51-53]. In contrast, other genes found to be activated, such as TNF, may promote degenerative processes. TNF encodes tumor necrosis factor alpha (TNF$\alpha$ ), a proinflammatory cytokine that exacerbates both $A \beta$ and tau pathologies in vivo [54]. However, the roles of cytokines like IFN-y and TNF- $\alpha$ are controversial in AD [55].

The upstream activated genes identified from the translational efficiency DEGs, PTF1A (see above) and PRKCG, are both probably protective. Protein kinase $\mathrm{C} \gamma$, which is encoded by PRKCG, can stimulate APP processing by $\alpha$-secretase to produce soluble fragments of APP and reduce $A \beta$ accumulation [56]. In contrast, we did not detect any prominent upstream gene regulation in the Tg2576 mice as might be expected from the uninformative functional enrichment 
analysis. Collectively, our functional analyses reinforce the conclusion that the CVN and Tg2576 models exhibit differential cortical brain gene regulation at six months of age.

Regulated genes in CVN mice reveal a signature of microglia responding to $A \beta$

To extend the functional analysis further, we used IdMiner, a tool that we developed inhouse (manuscript in preparation; https://github.com/sradiouy/ldMiner) to enhance interpretation of DEGs. This software is a text-mining tool that captures previously reported associations between gene lists and user-defined terms using the PubMed database. We found that among up-regulated genes in CVN mice at both the transcriptome and translatome level there was a clear signature of disease-associated microglia [20]. This signature included genes such as TREM2, TYROBP, TLR2, CD68, GPR84, GPNMB, ITGAX, ITGB2, LPL, CLEC7A, CST7 and CCL6 [20,21,57-60]. All these genes encode transmembrane proteins that are highly expressed in a microglial subpopulation that specifically responds to neurodegeneration. Overexpression of these markers orchestrates clearance of $A \beta$ by a subpopulation of disease-associated microglia $[20,57,61]$. This signature is part of the immune system response in $A D$, a statistically overrepresented function among up-regulated gene networks at both the transcriptome and translatome levels (Fig. S11 and S12).

Other genes up-regulated at both the transcriptome and translatome levels included those expressed primarily either in non-neuronal or neuronal cells, but not in both. For example, GFAP and SERPIN3 are overexpressed in astrocytes in AD [62-65]. Solute carrier family members and hippocalcin-like proteins were also up-regulated, in accordance with their possible neuroprotective functions in AD [66,67]. Additionally, we found increased expression of MID1, which encodes a member of the MID1 protein complex that binds to and accelerates APP mRNA translation through an mTOR-dependent pathway [68]. The tyrosine kinase gene, FGR, was also up-regulated at both transcriptional and translational levels. Fgr is able to bind tau, and although functional consequences of this interaction are not well understood [69], the Fgr paralog, Fyn, binds and phosphorylates tau [70] causing neurotoxicity [71,72].

An analysis of the genes up-regulated specifically at the translatome level revealed other examples of $A D$-associated genes. Examples include the histocompatibility 2 class II antigen $A$ gene, $H 2-A B 1$, a marker for disease-associated microglia $[57,58]$, and complement components $4 a$ and $4 b$, which were up-regulated as previously described in response to $A \beta$ plaque increase [65]. The CSF3R gene was also up-regulated at the translatome level, as expected, since it is 
highly expressed in early stages of AD [73]. Deficiency in G-CSF, a ligand for the receptor encoded by CSF3R, has a deep impact in hippocampal structure and function leading to disruption in memory formation and impaired behavioral performance [74]. Likewise, injected GCSF acts as a neurotrophic factor and induces astrocytic and microglial activation [75,76], so elevated CSF3R expression may signify a response mechanism to mitigate neurodegeneration.

When studying the list of up-regulated genes particularly at translational efficiency level, we detected several notable genes: SERPINA3G, FRMD4A, RRAS2, AV2, ADAM12, PPARG, MID1, LDLRAD3 and CD44. Some of these genes are associated with protective or beneficial functions. For example, FRMD4A, PPARG and RRAS2 have been shown to reduce high levels of $A \beta$ production [77-80], while $A D A M 12, M I D 1$ and $L D L R A D 3$ influence $A \beta$ production or neurotoxicity $[68,81,82]$.

Regarding down-regulated genes, we also found examples related to $A \beta$ accumulation. CD59A (complement defense 59A) was down-regulated at the transcriptome level, as might be expected in response to $A \beta$, and could contribute to neuronal vulnerability and loss $[83,84]$. Calbindin 2 (calretinin; CALB2) positive interneurons are specifically decreased as early targets of $A \beta$ accumulation in the hippocampus [85] and in the current study its expression was downregulated at the transcriptome and translatome levels. PIN4 was also down-regulated at both levels in accordance with the decrease observed for Pin1, a paralog gene, which plays a role in the accumulation of $A \beta$ [86-88] and tau [89,90]. Other down-regulated genes that may be germane to neurodegeneration include RPLPO and IGF2 [7,91], while genes like SLC17A8 and TNC (tenascin-C) may have been down-regulated to ameliorate pathology [92].

\section{Tg2576 mice differentially express genes associated with APP metabolism}

The number of DEGs in Tg2576 mice was much less than in CVN mice. The Toll like receptor 6 gene (TLR6) was up-regulated at both the transcriptome and translatome levels. TIr6 can dimerize with TIr4 and interact with CD36 to bind $A \beta$ and activate microglia, and thereby promote neurodegeneration [93]. Calpain 11 was also up-regulated at the transcriptome level, as expected since calpains are hyperactivated in AD [94,95]. CDK5RAP1, an inhibitor of Cdk5, was also up-regulated and could have a protective effect since Cdk5 activation causes hyperphosphorylation of APP and tau leading to plaques and tangles [96-98]. Also, Cdk5 has been described as a mediator of $A \beta$-induced neuronal cell cycle reentry that leads to neurodegeneration [99]. 
At the translatome level, evidence of other interesting up-regulated genes was found. Apolipoprotein D, which has a neuroprotective effect [100] and is induced in hippocampal cells in response to $A \beta$ [101], was translationally increased. Another gene with a neuroprotective function up-regulated at the translatome level encodes Metallothionein 3, which is expressed by astrocytes and is thought to facilitate $A \beta$ uptake [102], although this role remains controversial with opposite findings in vitro and in vivo and with different mouse models. For example, a study using the Tg2576 mice model shows that Metallothionein 3 could have opposite effects depending on gender, brain region and age [103]. Genes up-regulated exclusively at the level of translational efficiency were related to $A \beta$ production and disease. Examples include SERF2, a positive regulator of amyloid protein aggregation [104,105], and HRAS2, an apparent AD biomarker that is stimulated by $A \beta$ and produces a reduction in LTP [78].

Some transcriptionally down-regulated genes confirmed what was expected from previous reports. For example, KLK6 encodes a peptidase that cleaves APP and is down-regulated in the cortex of human postmortem samples of AD patients compared to controls [106,107]. The somatostatin receptor 5 was down-regulated at both the transcriptome and translatome level, consistent with the decreased levels reported for these receptors in the cortex of AD patients $[108,109]$. The FABP5 gene was found to be down-regulated at the translational efficiency level as expected since a Fabp5 deficiency is associated with increased vulnerability to cognitive deficits in mice with APP pathology [110,111]. Thus, Tg2576 mice showed differentially expressed genes associated with APP metabolism at both the transcriptome and translatome level.

Regulated functions common to both CVN and Tg2576 mice are involved in APP metabolism

We next compared the DEGs detected for CVN and Tg2576 mice using a FC cutoff of 1 to explore commonalities shared by both mouse models (Table 2). Common genes were rare, representing $<10 \%$ of the genes in our DEG list. When comparing up-regulated genes at the transcriptome level between CVN (282 genes) and Tg2576 (195 genes) mice, we found 25 shared genes. Of those, 19 are classified as predicted genes. Exhaustive analysis revealed that those genes mainly encode Zinc finger and a-takusan-like proteins, but they also include a long noncoding RNA (Gm26650). a-takusan proteins represent a large family that regulates synaptic activity and reportedly can mitigate $A \beta$-induced synaptic loss [112,113]. Among the common and annotated genes, we found $L R R C 37 A$, a leucine-rich repeat 
containing gene that encodes a plasma membrane protein involved in intracellular vesicle trafficking [114] and OSMR (Oncostatin M Receptor). LRRC37A was previously associated with $\mathrm{AD}$ because of its many SNPs detected in genome-wide association studies of APOE4 carriers and its genomic location adjacent to the tau gene, MAPT [115]. On the other hand, it has been reported that Oncostatin $M$ is neuroprotective against $A \beta$ toxicity [116].

When exploring the translationally up-regulated genes shared by both transgenic models, several interesting examples were noticed. Due to the small number of such genes in Tg2576 mice (66 genes, Table 2), we only found 6 genes in common. However, among them we found LRRC37A and a predicted gene (GM3173) annotated as an a-takusan-like protein (see above). Other interesting genes found were GFAP, and Hemoglobin alpha 1 and 2. Glial fibrillary acidic protein (GFAP) is an intermediate filament protein highly expressed in the reactive astrocytes that surround $A \beta$ plaques [62,117]. Hemoglobin alpha 1 and 2 (encoded by $H B A-A 1$ and $H B A-A 2$ ), is expressed by neurons [118], and can bind $A \beta$ and co-localize with plaques $[119,120]$.

We found 13 down-regulated genes common to CVN and Tg2576 mice, 8 of which were down-regulated at the transcriptome level and 5 of which were down-regulated translationally. Here we highlight TMEM59L, which was down-regulated transcriptionally and encodes transmembrane protein 59-like, an important paralog of TMEM59. TMEM59 has been identified as a novel modulator of APP shedding, controlling APP post-translational modification, trafficking and cleavage [121]. More recently, it has been reported that TMEM59 interacts with TREM2 (see above and Discussion), and that TMEM59 homeostasis is regulated by TREM2 in order to control microglia activity [122]. Common genes down-regulated at the translatome level include ribosomal proteins and ribosome biogenesis factors (Rpl5, Rpl32 and Wbscr22), the fatty acid binding protein 5 (FABP5) and adaptor related protein complex 4 (AP4S1). It has been reported that the adaptor protein 4 interacts with APP, and that the disruption of this interaction stimulates APP cleavage and $A \beta$ production [123].

Finally, despite the low identity overlap of DEGs in CVN versus Tg2576 mice, we also observed biological functions shared by the two AD mouse model strains. For example, several genes affected in each strain are associated with APP and A $\beta$ metabolism, either with neuroprotective or neurotoxic functions (Fig. 7).

\section{DISCUSSION}


We used RNA-Seq and Ribo-Seq to explore transcriptional and translational gene expression regulation, respectively, in the brain of two transgenic mouse models of AD. Studies of translation regulation using Ribo-Seq in mouse brain tissue have been sparse (see examples in [124-128]), and, to our knowledge, our work represents the first approach in AD models. Both transgenic mice used in this study are amyloid models since each strain has a transgenic insertion of the APP gene with specific mutations that increase levels of $A \beta$ and amyloid plaques (Table 1). Animals were euthanized at 6 months of age, when CVN mice are asymptomatic both behaviorally

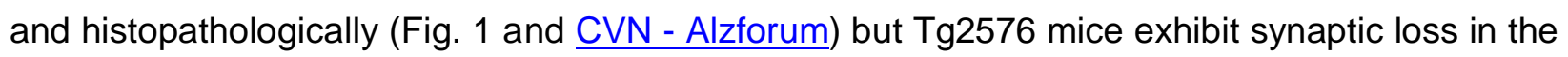
$\mathrm{CA} 1$ region of the hippocampus, reduced long term potentiation in the dentate gyrus, and a variety of cognitive impairments (Fig. 1 and Tg2576 - Alzforum).

The isolated total RNA and ribosome footprints obtained from the brain cortex (Fig. S1) yielded more than 20 and 120 million paired-end and single-end reads, respectively (Table S1). We specifically used the brain cortex, a region highly degenerated and pathologically compromised in both humans with $\mathrm{AD}$ and murine models of the disease. As anticipated, around $80 \%$ of the ribosome footprints samples were rRNA fragments derived from the RNAse digestion. We therefore resorted to deep sequencing to obtain workable amounts of non-rRNA reads. By doing so, we obtained more than 10 million ribosome footprints mapping over mRNAs in each sample (Table S1) and we defined expression levels for more than 14 thousand genes in each transgenic strain. As expected, almost all genes that we detected were found at both the transcriptome and translatome levels (Fig. S2). By studying mapping features and read periodicity, we separated transcriptome-derived from translatome-derived reads (Fig. S4 and S5). For example, translatome-derived reads show the classical three nucleotide mapping pattern periodicity not detected in transcriptome-derived reads, providing evidence of solid transcriptome and translatome datasets.

Differential gene expression analysis was performed over transcriptome and translatome samples separately, comparing transgenic mice versus WT, to explore deregulated genes in each model. However, considering that differences at the translatome level could be explained by regulation at the transcriptome level, we estimated translational efficiency as the ratio between translatome and transcriptome levels to specifically identify translational regulation events [23] (Fig. 2 and 3). Despite using different animals as replicates, which could generate considerable biological variation, samples clustered as expected as evidenced by principal component analysis (Fig. S6). Also, we were able to define lists of genes with a significant statistical difference between genotypes at $p$-adjusted values $<0.05$ (Table 2). Expression levels of DEGs also 
separates samples as expected and shows the different levels of regulation observed, especially when analyzing translational efficiency regulation (Fig. 4). As a control comparison, we also explored differential gene expression between WT animals, and there is only a limited overlap with previously defined DEGs and the enriched biological functions observed were either not related to the results previously discussed or absent (Fig. S13 and S14).

The functional analysis of regulated genes involves different approaches and techniques. We used standard gene ontology and functional enrichment tools, namely IPA and STRING, which revealed a clear signature of decreased neurodegenerative-related process and increased neuroprotective-related functions, particularly for the CVN strain (Fig. 5 and 6). Secondly, we complemented the analysis with an in-house developed tool (https://github.com/sradiouy/ldMiner) to deeply explore DEGs lists in order to find relevant associations between genes and biological functions related to pathology. By using this approach, we detected several genes associated either with the neurodegenerative and neurotoxicity phenotype or with protective and beneficial functions (see below).

In CVN mice we identified a clear gene signature common in disease-associated microglia (DAM). These genes mainly encode transmembrane proteins that were up-regulated at both transcriptome and translatome levels, and mediate immune system processes (Fig. S11 and S12). Earlier studies of other AD mouse models at the same or older ages suggest that the main functions of this DAM population are to locate and clear $A \beta$ plaques $[20,21,57,58]$. It is noteworthy that a DAM population is present in CVN mice at a stage when they do not show any phenotypic signs of disease. Among the genes present in this signature are TREM2 and TYROBP, both of which were up-regulated (transcriptome level: $F C=2.12$ and 1.66 , $p$-adjusted value $<1.18 \mathrm{E}-15$ and <6.22E-4, respectively; translatome level: $\mathrm{FC}=1.90$ and 1.72 , $\mathrm{p}$-adjusted value $<4.25 \mathrm{E}-8$ and $<1.39 E-4$, respectively). The TREM2/TYROBP complex expressed in microglia is necessary to prevent $A \beta$ accumulation and diffusion [20,129-131]. TREM2/TYROBP-dependent cell activation seems to be beneficial [132], while TREM2 deficiency impairs cellular metabolism and promotes increased autophagy in microglia in an AD mouse model [133]. Concordantly, in CVN mice we found several members of the TYROBP AD-related pathway $[59,134]$ regulated at the transcriptome and/or translatome level (Fig. S15). Regarding TREM2, transgenic overexpression in an $A D$ mouse model of the human version of this gene modified the morphological and functional responses of microglia, which resulted in amelioration of the pathology and memory deficits [135]. Interestingly, it has been reported that TREM2 interacts with TREM59 and modulates microglia activation [122]. Here we found TREM59L as a down-regulated gene at the 
transcriptional level in both transgenic mice models (CVN: FC $=-1.89$ and $p$-adjusted value $<3.56 E-28 ;$ Tg2576: FC = -1.29 and p-adjusted value <0.01). Regarding functional interpretation of DEGs and considering the upregulated genes at the translational level, two different sets of genes were observed. One set associated with protective functions, such as reducing $A \beta$ production, and others related to the high levels of $A \beta$ and neurotoxicity. $A$ similar interpretation was made from the lists of down-regulated genes.

Although Tg2576 mice experience cognitive deficits at 6 months, amyloid plaques typically do not appear in this strain until 11-13 months (Fig. 1 and Tg2576 - Alzforum). Nevertheless, we found a group of genes that were regulated at the transcriptome and/or translatome levels in the 6 month old Tg2576 mice, and have been reported to be altered in response to the presence of $A \beta$. In light of the dearth of plaques, we suspect that expression of these genes was affected by accumulation of $A \beta$ oligomers in cortical brain tissue. Also, as observed for CVN mice, we found genes associated with neuroprotective functions and others with a neurodegenerative phenotype related to APP metabolism (Figure 7).

We also explored DEGs that were common to both AD strains at the transcriptome or translatome levels. Despite the facts that CVN and Tg2576 mice are derived from different WT parental strains (Table 1), and exhibit different patterns of phenotypic alterations (Fig. 1A) and distinct regulation levels (Table 2), it is noteworthy that they share genes that are regulated transcriptionally and translationally. These DEGs, such as a-takusan proteins, LRRC37A, OSMR, GFAP, hemoglobin alpha 1 and 2, TMEM59L and FABP5, are seen at early stages of disease and modulate functions that could be associated with $A D$ pathology. Despite the lack of plaques in 6 month old CVN mice, most of the DEGs common to both strains are implicated in APP metabolism in a neuroprotective fashion that responds to $A \beta$ accumulation.

It is important to note that we analyzed gene expression of a complex brain tissue that contains a heterogeneous population of cells. In addition to specific regulation events occurring in particular cell types that could be underestimated here, the high abundance of neurons adds an extra layer of complexity, because of the large dimensions and high polarity these cells can achieve. Considering the relevant contribution of local regulation events in neurons [136-139] and in particular previous evidence in the context of AD [11], we cannot exclude the possibility that local protein synthesis events may regulate neuron response to local stimulus in the brain cortices. To specifically disentangle these regulatory events, one would need to conduct new experiments using tools designed to examine functional genomics in specific neuronal compartments [17]. 
Overall, this study documents the contribution of the different layers of gene expression regulation involved with $A D$ pathology, especially at the level of translation. The two amyloidproducing animal models used here show relevant gene expression regulation at the transcriptome and translatome levels. Although the number of differentially expressed genes was markedly different, both models reveal several regulated genes associated with APP and A metabolism. However, we noticed that each transgenic mouse was able to modulate different groups of genes that represent specific biological functions. For example, although the 6 month old CVN mice that we used were asymptomatic for AD-like traits, their gene expression profiles were skewed towards neuroprotection. Degeneration processes were decreased, protective functions were increased, and a specific microglia subpopulation was induced as a presumptive response to $A \beta$ accumulation prior to plaque formation. On the other hand, 6 month old Tg2576 mice displayed signs of simultaneous neuroprotection and neurodegeneration. Perhaps this reflects a more rapidly progressing $A D$-like phenotype manifest as cognitive impairment at that

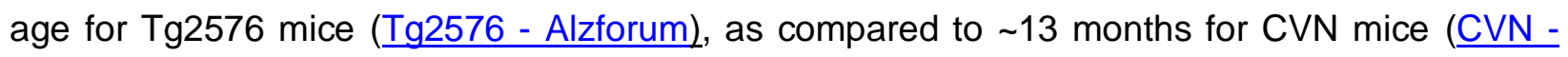
Alzforum).

Recent advances in genomic views of translation have been essential to widen our current concepts about the dynamic properties of protein translation as a process. More specifically, such advances increase the relevance that regulation of translation has on particular sets of mRNAs, and by extension on proteostasis. Besides pointing to novel transcriptional regulation events in $A D$ disease models, here we provide evidence that translation is important in regulating key $A D$ related genes at early asymptomatic stages. Several of the dysregulated pathways observed here will need further study to elucidate regulation mechanisms, but their identification implies that both translation and transcription are dysregulated during both pre-symptomatic and symptomatic phases of $A D$.

\section{ACKNOWLEDGMENTS}

We thank members of Sotelo-Silveira lab for the results discussion and intellectual input. We also thank members of Bloom lab, especially Drs. Andrés Norambuena and Antonia Silva, for their support with wet lab experiments, and Dr. Dora Bigler-Wang and Nutan Shivange for handling mice and brain dissections. We also acknowledge the following sources of financial support: PhD fellowships from Agencia Nacional de Investigación e Innovación (ANII) to G.E. (POS_NAC_2016_1_129959), Programa de Desarrollo de las Ciencias Básicas (PEDECIBA) to G.E. and J.R.S-S., PROLAB travel grant (PABMB/ASBMB/IUBMB) to G.E.; the Owen's Family 
Foundation, the Cure Alzheimer's Fund and the Rick Sharp Alzheimer's Foundation to G.S.B., J.S.L. and E.R.S., and NIH grant RF1 AG051085 to G.S.B.

\section{CONFLICT OF INTEREST}

The authors have no conflict of interest to report.

\section{AUTHOR CONTRIBUTIONS}

J.R.S-S. and G.S.B. conceived the project, designed and supervised the research. J.S.L. and E.R.S. contributed to the project design and intellectual content. G.E. performed the experiments. G.E. and E.R.S. analyzed data. G.E., J.R.S-S. and G.S.B. wrote the paper. All authors approved the manuscript.

\section{REFERENCES}

[1] Bloom GS (2014) Amyloid- $\beta$ and tau: the trigger and bullet in Alzheimer disease pathogenesis. JAMA Neurol 71, 505-508.

[2] Kapur M, Monaghan CE, Ackerman SL (2017) Regulation of mRNA Translation in NeuronsA Matter of Life and Death. Neuron 96, 616-637.

[3] Delaidelli A, Jan A, Herms J, Sorensen PH (2019) Translational control in brain pathologies: biological significance and therapeutic opportunities. Acta Neuropathol 137, 535-555.

[4] Taymans J-M, Nkiliza A, Chartier-Harlin M-C (2015) Deregulation of protein translation control, a potential game-changing hypothesis for Parkinson's disease pathogenesis. Trends Mol Med 21, 466-472.

[5] Eshraghi M, Karunadharma PP, Blin J, Shahani N, Ricci EP, Michel A, Urban NT, Galli N, Sharma M, Ramírez-Jarquín UN, Florescu K, Hernandez J, Subramaniam S (2021) Mutant Huntingtin stalls ribosomes and represses protein synthesis in a cellular model of Huntington disease. Nat Commun 12, 1461.

[6] Cefaliello C, Penna E, Barbato C, Di Ruberto G, Mollica MP, Trinchese G, Cigliano L, Borsello T, Chun JT, Giuditta A, Perrone-Capano C, Miniaci MC, Crispino M (2020) Deregulated Local Protein Synthesis in the Brain Synaptosomes of a Mouse Model for Alzheimer's Disease. Mol Neurobiol 57, 1529-1541.

[7] Evans HT, Benetatos J, van Roijen M, Bodea L-G, Götz J (2019) Decreased synthesis of ribosomal proteins in tauopathy revealed by non-canonical amino acid labelling. EMBO J 
38, e101174.

[8] Li C, Götz J (2017) Somatodendritic accumulation of Tau in Alzheimer's disease is promoted by Fyn-mediated local protein translation. EMBO J 36, 3120-3138.

[9] Banerjee S, Ferdosh S, Ghosh AN, Barat C (2020) Tau protein- induced sequestration of the eukaryotic ribosome: Implications in neurodegenerative disease. Sci Rep 10, 5225.

[10] Ghosh A, Mizuno K, Tiwari SS, Proitsi P, Gomez Perez-Nievas B, Glennon E, MartinezNunez RT, Giese KP (2020) Alzheimer's disease-related dysregulation of mRNA translation causes key pathological features with ageing. Transl Psychiatry 10, 192.

[11] Baleriola J, Walker CA, Jean YY, Crary JF, Troy CM, Nagy PL, Hengst U (2014) Axonally synthesized ATF4 transmits a neurodegenerative signal across brain regions. Cell 158, 1159-1172.

[12] Koren SA, Hamm MJ, Meier SE, Weiss BE, Nation GK, Chishti EA, Arango JP, Chen J, Zhu H, Blalock EM, Abisambra JF (2019) Tau drives translational selectivity by interacting with ribosomal proteins. Acta Neuropathol 137, 571-583.

[13] Simone R, Javad F, Emmett W, Wilkins OG, Almeida FL, Barahona-Torres N, ZarebaPaslawska J, Ehteramyan M, Zuccotti P, Modelska A, Siva K, Virdi GS, Mitchell JS, Harley J, Kay VA, Hondhamuni G, Trabzuni D, Ryten M, Wray S, Preza E, Kia DA, Pittman A, Ferrari R, Manzoni C, Lees A, Hardy JA, Denti MA, Quattrone A, Patani R, Svenningsson P, Warner TT, Plagnol V, Ule J, de Silva R (2021) MIR-NATs repress MAPT translation and aid proteostasis in neurodegeneration. Nature 594, 117-123.

[14] Norambuena A, Wallrabe H, McMahon L, Silva A, Swanson E, Khan SS, Baerthlein D, Kodis E, Oddo S, Mandell JW, Bloom GS (2017) mTOR and neuronal cell cycle reentry: How impaired brain insulin signaling promotes Alzheimer's disease. Alzheimers Dement 13, $152-167$.

[15] Norambuena A, Wallrabe H, Cao R, Wang DB, Silva A, Svindrych Z, Periasamy A, Hu S, Tanzi RE, Kim DY, Bloom GS (2018) A novel lysosome-to-mitochondria signaling pathway disrupted by amyloid- $\beta$ oligomers. EMBO J 37, e100241.

[16] Switon K, Kotulska K, Janusz-Kaminska A, Zmorzynska J, Jaworski J (2017) Molecular neurobiology of mTOR. Neuroscience 341, 112-153.

[17] Di Paolo A, Garat J, Eastman G, Farias J, Dajas-Bailador F, Smircich P, Sotelo-Silveira JR (2021) Functional Genomics of Axons and Synapses to Understand Neurodegenerative Diseases. Front Cell Neurosci 15, 686722.

[18] Castanho I, Murray TK, Hannon E, Jeffries A, Walker E, Laing E, Baulf H, Harvey J, Bradshaw L, Randall A, Moore K, O’Neill P, Lunnon K, Collier DA, Ahmed Z, O'Neill MJ, Mill J (2020) Transcriptional Signatures of Tau and Amyloid Neuropathology. Cell Rep 30, 2040-2054.e5.

[19] Wan Y-W, Al-Ouran R, Mangleburg CG, Perumal TM, Lee TV, Allison K, Swarup V, Funk CC, Gaiteri C, Allen M, Wang M, Neuner SM, Kaczorowski CC, Philip VM, Howell GR, Martini-Stoica H, Zheng H, Mei H, Zhong X, Kim JW, Dawson VL, Dawson TM, Pao P-C, Tsai L-H, Haure-Mirande J-V, Ehrlich ME, Chakrabarty P, Levites Y, Wang X, Dammer EB, Srivastava G, Mukherjee S, Sieberts SK, Omberg L, Dang KD, Eddy JA, Snyder P, Chae Y, Amberkar S, Wei W, Hide W, Preuss C, Ergun A, Ebert PJ, Airey DC, Mostafavi S, Yu L, Klein $\mathrm{H}-\mathrm{U}$, Accelerating Medicines Partnership-Alzheimer's Disease Consortium, Carter GW, Collier DA, Golde TE, Levey AI, Bennett DA, Estrada K, Townsend TM, Zhang B, Schadt E, De Jager PL, Price ND, Ertekin-Taner N, Liu Z, Shulman JM, Mangravite LM, Logsdon BA (2020) Meta-Analysis of the Alzheimer's Disease Human Brain Transcriptome and Functional Dissection in Mouse Models. Cell Rep 32, 107908.

[20] Keren-Shaul H, Spinrad A, Weiner A, Matcovitch-Natan O, Dvir-Szternfeld R, Ulland TK, David E, Baruch K, Lara-Astaiso D, Toth B, Itzkovitz S, Colonna M, Schwartz M, Amit I (2017) A Unique Microglia Type Associated with Restricting Development of Alzheimer's 
Disease. Cell 169, 1276-1290.e17.

[21] Pickett EK, Herrmann AG, McQueen J, Abt K, Dando O, Tulloch J, Jain P, Dunnett S, Sohrabi S, Fjeldstad MP, Calkin W, Murison L, Jackson RJ, Tzioras M, Stevenson A, d'Orange M, Hooley M, Davies C, Colom-Cadena M, Anton-Fernandez A, King D, Oren I, Rose J, McKenzie C-A, Allison E, Smith C, Hardt O, Henstridge CM, Hardingham GE, Spires-Jones TL (2019) Amyloid Beta and Tau Cooperate to Cause Reversible Behavioral and Transcriptional Deficits in a Model of Alzheimer's Disease. Cell Rep 29, 3592-3604.e5.

[22] Kang SS, Ebbert MTW, Baker KE, Cook C, Wang X, Sens JP, Kocher J-P, Petrucelli L, Fryer JD (2018) Microglial translational profiling reveals a convergent APOE pathway from aging, amyloid, and tau. J Exp Med 215, 2235-2245.

[23] Ingolia NT (2014) Ribosome profiling: new views of translation, from single codons to genome scale. Nat Rev Genet 15, 205-213.

[24] Ingolia NT (2016) Ribosome Footprint Profiling of Translation throughout the Genome. Cell 165, 22-33.

[25] Eastman G, Smircich P, Sotelo-Silveira JR (2018) Following Ribosome Footprints to Understand Translation at a Genome Wide Level. Comput Struct Biotechnol J 16, 167-176.

[26] Wilcock DM, Lewis MR, Van Nostrand WE, Davis J, Previti ML, Gharkholonarehe N, Vitek MP, Colton CA (2008) Progression of amyloid pathology to Alzheimer's disease pathology in an amyloid precursor protein transgenic mouse model by removal of nitric oxide synthase 2. J Neurosci 28, 1537-1545.

[27] Hsiao K, Chapman P, Nilsen S, Eckman C, Harigaya Y, Younkin S, Yang F, Cole G (1996) Correlative memory deficits, Abeta elevation, and amyloid plaques in transgenic mice. Science 274, 99-102.

[28] Smircich P, Eastman G, Bispo S, Duhagon MA, Guerra-Slompo EP, Garat B, Goldenberg S, Munroe DJ, Dallagiovanna B, Holetz F, Sotelo-Silveira JR (2015) Ribosome profiling reveals translation control as a key mechanism generating differential gene expression in Trypanosoma cruzi. BMC Genomics 16, 443.

[29] Di Paolo A, Eastman G, Mesquita-Ribeiro R, Farias J, Macklin A, Kislinger T, Colburn N, Munroe D, Sotelo Sosa JR, Dajas-Bailador F, Sotelo-Silveira JR (2020) PDCD4 regulates axonal growth by translational repression of neurite growth-related genes and is modulated during nerve injury responses. RNA 26, 1637-1653.

[30] Ingolia NT, Brar GA, Rouskin S, McGeachy AM, Weissman JS (2012) The ribosome profiling strategy for monitoring translation in vivo by deep sequencing of ribosomeprotected mRNA fragments. Nat Protoc 7, 1534-1550.

[31] Andrews S (2015) FastQC: A Quality Control Tool for High Throughput Sequence Data.

[32] Langmead B, Salzberg SL (2012) Fast gapped-read alignment with Bowtie 2. Nat Methods 9, 357-359.

[33] Liao Y, Smyth GK, Shi W (2014) featureCounts: an efficient general purpose program for assigning sequence reads to genomic features. Bioinformatics 30, 923-930.

[34] Robinson MD, McCarthy DJ, Smyth GK (2010) edgeR: a Bioconductor package for differential expression analysis of digital gene expression data. Bioinformatics 26, 139-140.

[35] Xiao Z, Zou Q, Liu Y, Yang X (2016) Genome-wide assessment of differential translations with ribosome profiling data. Nat Commun 7, 11194.

[36] Krämer A, Green J, Pollard J Jr, Tugendreich S (2014) Causal analysis approaches in Ingenuity Pathway Analysis. Bioinformatics 30, 523-530.

[37] Szklarczyk D, Franceschini A, Wyder S, Forslund K, Heller D, Huerta-Cepas J, Simonovic M, Roth A, Santos A, Tsafou KP, Kuhn M, Bork P, Jensen LJ, von Mering C (2015) STRING v10: protein-protein interaction networks, integrated over the tree of life. Nucleic Acids Res 43, D447-52.

[38] Raudvere U, Kolberg L, Kuzmin I, Arak T, Adler P, Peterson H, Vilo J (2019) g:Profiler: a 
web server for functional enrichment analysis and conversions of gene lists (2019 update). Nucleic Acids Res 47, W191-W198.

[39] Carbon S, Ireland A, Mungall CJ, Shu S, Marshall B, Lewis S, AmiGO Hub, Web Presence Working Group (2009) AmiGO: online access to ontology and annotation data. Bioinformatics 25, 288-289.

[40] Walter W, Sánchez-Cabo F, Ricote M (2015) GOplot: an R package for visually combining expression data with functional analysis. Bioinformatics 31, 2912-2914.

[41] Yamaguchi T, Yamauchi Y, Furukawa K, Ohmi Y, Ohkawa Y, Zhang Q, Okajima T, Furukawa K (2016) Expression of B4GALNT1, an essential glycosyltransferase for the synthesis of complex gangliosides, suppresses BACE1 degradation and modulates APP processing. Sci Rep 6, 34505.

[42] Bernardo A, Harrison FE, McCord M, Zhao J, Bruchey A, Davies SS, Jackson Roberts L 2nd, Mathews PM, Matsuoka Y, Ariga T, Yu RK, Thompson R, McDonald MP (2009) Elimination of GD3 synthase improves memory and reduces amyloid-beta plaque load in transgenic mice. Neurobiol Aging 30, 1777-1791.

[43] Yang Y, Quitschke WW, Vostrov AA, Brewer GJ (1999) CTCF is essential for up-regulating expression from the amyloid precursor protein promoter during differentiation of primary hippocampal neurons. J Neurochem 73, 2286-2298.

[44] McGill BE, Barve RA, Maloney SE, Strickland A, Rensing N, Wang PL, Wong M, Head R, Wozniak DF, Milbrandt J (2018) Abnormal Microglia and Enhanced Inflammation-Related Gene Transcription in Mice with Conditional Deletion of Ctcf in CaMK2a-Cre-Expressing Neurons. J Neurosci 38, 200-219.

[45] Silva AC, Lemos C, Gonçalves FQ, Pliássova AV, Machado NJ, Silva HB, Canas PM, Cunha RA, Lopes JP, Agostinho P (2018) Blockade of adenosine A receptors recovers early deficits of memory and plasticity in the triple transgenic mouse model of Alzheimer's disease. Neurobiol Dis 117, 72-81.

[46] Viana da Silva S, Haberl MG, Zhang P, Bethge P, Lemos C, Gonçalves N, Gorlewicz A, Malezieux M, Gonçalves FQ, Grosjean N, Blanchet C, Frick A, Nägerl UV, Cunha RA, Mulle C (2016) Early synaptic deficits in the APP/PS1 mouse model of Alzheimer's disease involve neuronal adenosine A2A receptors. Nat Commun 7, 11915.

[47] Blom ES, Wang Y, Skoglund L, Hansson AC, Ubaldi M, Lourdusamy A, Sommer WH, Mielke M, Hyman BT, Heilig M, Lannfelt L, Nilsson LNG, Ingelsson M (2010) Increased mRNA Levels of TCF7L2 and MYC of the Wnt Pathway in Tg-ArcSwe Mice and Alzheimer's Disease Brain. Int J Alzheimers Dis 2011, 936580.

[48] Kawanishi S, Takata K, Itezono S, Nagayama H, Konoya S, Chisaki Y, Toda Y, Nakata S, Yano Y, Kitamura Y, Ashihara E (2018) Bone-Marrow-Derived Microglia-Like Cells Ameliorate Brain Amyloid Pathology and Cognitive Impairment in a Mouse Model of Alzheimer's Disease. J Alzheimers Dis 64, 563-585.

[49] Boissonneault V, Filali M, Lessard M, Relton J, Wong G, Rivest S (2009) Powerful beneficial effects of macrophage colony-stimulating factor on beta-amyloid deposition and cognitive impairment in Alzheimer's disease. Brain 132, 1078-1092.

[50] Xiao D, Liu X, Zhang M, Zou M, Deng Q, Sun D, Bian X, Cai Y, Guo Y, Liu S, Li S, Shiang E, Zhong H, Cheng L, Xu H, Jin K, Xiang M (2018) Direct reprogramming of fibroblasts into neural stem cells by single non-neural progenitor transcription factor Ptf1a. Nat Commun 9, 2865.

[51] He Z, Yang Y, Xing Z, Zuo Z, Wang R, Gu H, Qi F, Yao Z (2020) Intraperitoneal injection of IFN- $\gamma$ restores microglial autophagy, promotes amyloid- $\beta$ clearance and improves cognition in APP/PS1 mice. Cell Death Dis 11, 440.

[52] Chakrabarty P, Ceballos-Diaz C, Beccard A, Janus C, Dickson D, Golde TE, Das P (2010) IFN-gamma promotes complement expression and attenuates amyloid plaque deposition in 
amyloid beta precursor protein transgenic mice. J Immunol 184, 5333-5343.

[53] Baron R, Nemirovsky A, Harpaz I, Cohen H, Owens T, Monsonego A (2008) IFN-gamma enhances neurogenesis in wild-type mice and in a mouse model of Alzheimer's disease. FASEB J 22, 2843-2852.

[54] Decourt B, Lahiri DK, Sabbagh MN (2017) Targeting Tumor Necrosis Factor Alpha for Alzheimer's Disease. Curr Alzheimer Res 14, 412-425.

[55] Zheng C, Zhou X-W, Wang J-Z (2016) The dual roles of cytokines in Alzheimer's disease: update on interleukins, TNF- $\alpha$, TGF- $\beta$ and IFN-y. Transl Neurodegener 5, 7.

[56] Argellati F, Domenicotti C, Passalacqua M, Janda E, Melloni E, Marinari UM, Pronzato MA, Ricciarelli R (2009) Protein kinase C-dependent alpha-secretory processing of the amyloid precursor protein is mediated by phosphorylation of myosin II-B. FASEB J 23, 1246-1251.

[57] Sala Frigerio C, Wolfs L, Fattorelli N, Thrupp N, Voytyuk I, Schmidt I, Mancuso R, Chen WT, Woodbury ME, Srivastava G, Möller T, Hudry E, Das S, Saido T, Karran E, Hyman B, Perry VH, Fiers M, De Strooper B (2019) The Major Risk Factors for Alzheimer's Disease: Age, Sex, and Genes Modulate the Microglia Response to A $\beta$ Plaques. Cell Rep 27, 12931306.e6.

[58] Mathys H, Adaikkan C, Gao F, Young JZ, Manet E, Hemberg M, De Jager PL, Ransohoff RM, Regev A, Tsai L-H (2017) Temporal Tracking of Microglia Activation in Neurodegeneration at Single-Cell Resolution. Cell Rep 21, 366-380.

[59] Zhang B, Gaiteri C, Bodea L-G, Wang Z, McElwee J, Podtelezhnikov AA, Zhang C, Xie T, Tran L, Dobrin R, Fluder E, Clurman B, Melquist S, Narayanan M, Suver C, Shah H, Mahajan M, Gillis T, Mysore J, MacDonald ME, Lamb JR, Bennett DA, Molony C, Stone DJ, Gudnason V, Myers AJ, Schadt EE, Neumann H, Zhu J, Emilsson V (2013) Integrated systems approach identifies genetic nodes and networks in late-onset Alzheimer's disease. Cell 153, 707-720.

[60] Audoy-Rémus J, Bozoyan L, Dumas A, Filali M, Lecours C, Lacroix S, Rivest S, Tremblay $M-E$, Vallières L (2015) GPR84 deficiency reduces microgliosis, but accelerates dendritic degeneration and cognitive decline in a mouse model of Alzheimer's disease. Brain Behav Immun 46, 112-120.

[61] Grubman A, Choo XY, Chew G, Ouyang JF, Sun G, Croft NP, Rossello FJ, Simmons R, Buckberry S, Landin DV, Pflueger J, Vandekolk TH, Abay Z, Zhou Y, Liu X, Chen J, Larcombe M, Haynes JM, McLean C, Williams S, Chai SY, Wilson T, Lister R, Pouton CW, Purcell AW, Rackham OJL, Petretto E, Polo JM (2021) Transcriptional signature in microglia associated with $A \beta$ plaque phagocytosis. Nat Commun 12, 3015.

[62] Kamphuis W, Middeldorp J, Kooijman L, Sluijs JA, Kooi E-J, Moeton M, Freriks M, Mizee MR, Hol EM (2014) Glial fibrillary acidic protein isoform expression in plaque related astrogliosis in Alzheimer's disease. Neurobiol Aging 35, 492-510.

[63] Tyagi E, Fiorelli T, Norden M, Padmanabhan J (2013) Alpha 1-Antichymotrypsin, an Inflammatory Protein Overexpressed in the Brains of Patients with Alzheimer's Disease, Induces Tau Hyperphosphorylation through c-Jun N-Terminal Kinase Activation. Int J Alzheimers Dis 2013, 606083.

[64] Hol EM, Roelofs RF, Moraal E, Sonnemans MAF, Sluijs JA, Proper EA, de Graan PNE, Fischer DF, van Leeuwen FW (2003) Neuronal expression of GFAP in patients with Alzheimer pathology and identification of novel GFAP splice forms. Mol Psychiatry 8, 786796.

[65] Wirz KTS, Bossers K, Stargardt A, Kamphuis W, Swaab DF, Hol EM, Verhaagen J (2013) Cortical beta amyloid protein triggers an immune response, but no synaptic changes in the APPswe/PS1dE9 Alzheimer's disease mouse model. Neurobiol Aging 34, 1328-1342.

[66] Lim Y-A, Giese M, Shepherd C, Halliday G, Kobayashi M, Takamatsu K, Staufenbiel M, Eckert A, Götz J (2012) Role of hippocalcin in mediating A $\beta$ toxicity. Biochim Biophys Acta 
1822, 1247-1257.

[67] Jamieson SE, White JK, Howson JMM, Pask R, Smith AN, Brayne C, Evans JG, Xuereb J, Cairns NJ, Rubinsztein DC, Blackwell JM (2005) Candidate gene association study of solute carrier family 11a members 1 (SLC11A1) and 2 (SLC11A2) genes in Alzheimer's disease. Neurosci Lett 374, 124-128.

[68] Matthes F, Hettich MM, Schilling J, Flores-Dominguez D, Blank N, Wiglenda T, Buntru A, Wolf H, Weber S, Vorberg I, Dagane A, Dittmar G, Wanker E, Ehninger D, Krauss S (2018) Inhibition of the MID1 protein complex: a novel approach targeting APP protein synthesis. Cell Death Discov 4, 4.

[69] Reynolds CH, Garwood CJ, Wray S, Price C, Kellie S, Perera T, Zvelebil M, Yang A, Sheppard PW, Varndell IM, Hanger DP, Anderton BH (2008) Phosphorylation regulates tau interactions with Src homology 3 domains of phosphatidylinositol 3-kinase, phospholipase Cgamma1, Grb2, and Src family kinases. J Biol Chem 283, 18177-18186.

[70] Lee G, Thangavel R, Sharma VM, Litersky JM, Bhaskar K, Fang SM, Do LH, Andreadis A, Van Hoesen G, Ksiezak-Reding H (2004) Phosphorylation of tau by fyn: implications for Alzheimer's disease. J Neurosci 24, 2304-2312.

[71] Seward ME, Swanson E, Norambuena A, Reimann A, Cochran JN, Li R, Roberson ED, Bloom GS (2013) Amyloid- $\beta$ signals through tau to drive ectopic neuronal cell cycle re-entry in Alzheimer's disease. J Cell Sci 126, 1278-1286.

[72] Ittner LM, Ke YD, Delerue F, Bi M, Gladbach A, van Eersel J, Wölfing H, Chieng BC, Christie MJ, Napier IA, Eckert A, Staufenbiel M, Hardeman E, Götz J (2010) Dendritic function of tau mediates amyloid-beta toxicity in Alzheimer's disease mouse models. Cell 142, 387-397.

[73] López González I, Garcia-Esparcia P, Llorens F, Ferrer I (2016) Genetic and Transcriptomic Profiles of Inflammation in Neurodegenerative Diseases: Alzheimer, Parkinson, Creutzfeldt-Jakob and Tauopathies. Int J Mol Sci 17, 206.

[74] Diederich K, Sevimli S, Dörr H, Kösters E, Hoppen M, Lewejohann L, Klocke R, Minnerup J, Knecht S, Nikol S, Sachser N, Schneider A, Gorji A, Sommer C, Schäbitz W-R (2009) The role of granulocyte-colony stimulating factor (G-CSF) in the healthy brain: a characterization of G-CSF-deficient mice. J Neurosci 29, 11572-11581.

[75] Rah W-J, Lee Y-H, Moon J-H, Jun H-J, Kang H-R, Koh H, Eom HJ, Lee JY, Lee YJ, Kim JY, Choi Y-Y, Park K, Kim MJ, Kim S-H (2017) Neuroregenerative potential of intravenous G-CSF and autologous peripheral blood stem cells in children with cerebral palsy: a randomized, double-blind, cross-over study. J Transl Med 15, 1-9.

[76] Song S, Kong X, Acosta S, Sava V, Borlongan C, Sanchez-Ramos J (2016) Granulocytecolony stimulating factor promotes brain repair following traumatic brain injury by recruitment of microglia and increasing neurotrophic factor expression. Restor Neurol Neurosci 34, 415-431.

[77] Martiskainen H, Viswanathan J, Nykänen N-P, Kurki M, Helisalmi S, Natunen T, Sarajärvi T, Kurkinen KMA, Pursiheimo J-P, Rauramaa T, Alafuzoff I, Jääskeläinen JE, Leinonen V, Soininen H, Haapasalo A, Huttunen HJ, Hiltunen M (2015) Transcriptomics and mechanistic elucidation of Alzheimer's disease risk genes in the brain and in vitro models. Neurobiol Aging 36, 1221.e15-28.

[78] Darcy MJ, Jin S-X, Feig LA (2014) R-Ras contributes to LTP and contextual discrimination. Neuroscience 277, 334-342.

[79] Heneka MT, Reyes-Irisarri E, Hüll M, Kummer MP (2011) Impact and Therapeutic Potential of PPARs in Alzheimer's Disease. Curr Neuropharmacol 9, 643-650.

[80] de la Monte SM, Wands JR (2006) Molecular indices of oxidative stress and mitochondrial dysfunction occur early and often progress with severity of Alzheimer's disease. $J$ Alzheimers Dis 9, 167-181. 
[81] Malinin NL, Wright S, Seubert P, Schenk D, Griswold-Prenner I (2005) Amyloid-beta neurotoxicity is mediated by FISH adapter protein and ADAM12 metalloprotease activity. Proc Natl Acad Sci U S A 102, 3058-3063.

[82] Ranganathan S, Noyes NC, Migliorini M, Winkles JA, Battey FD, Hyman BT, Smith E, Yepes M, Mikhailenko I, Strickland DK (2011) LRAD3, a novel low-density lipoprotein receptor family member that modulates amyloid precursor protein trafficking. J Neurosci 31, $10836-10846$.

[83] Kolev MV, Tediose T, Sivasankar B, Harris CL, Thome J, Morgan BP, Donev RM (2010) Upregulating CD59: a new strategy for protection of neurons from complement-mediated degeneration. Pharmacogenomics J 10, 12-19.

[84] Yang LB, Li R, Meri S, Rogers J, Shen Y (2000) Deficiency of complement defense protein CD59 may contribute to neurodegeneration in Alzheimer's disease. J Neurosci 20, 75057509.

[85] Baglietto-Vargas D, Moreno-Gonzalez I, Sanchez-Varo R, Jimenez S, Trujillo-Estrada L, Sanchez-Mejias E, Torres M, Romero-Acebal M, Ruano D, Vizuete M, Vitorica J, Gutierrez A (2010) Calretinin interneurons are early targets of extracellular amyloid-beta pathology in PS1/AbetaPP Alzheimer mice hippocampus. J Alzheimers Dis 21, 119-132.

[86] Pastorino L, Ma SL, Balastik M, Huang P, Pandya D, Nicholson L, Lu KP (2012) Alzheimer's disease-related loss of Pin1 function influences the intracellular localization and the processing of AßPP. J Alzheimers Dis 30, 277-297.

[87] Wang S, Simon BP, Bennett DA, Schneider JA, Malter JS, Wang D-S (2007) The significance of Pin1 in the development of Alzheimer's disease. J Alzheimers Dis 11, 1323.

[88] Pastorino L, Sun A, Lu P-J, Zhou XZ, Balastik M, Finn G, Wulf G, Lim J, Li S-H, Li X, Xia W, Nicholson LK, Lu KP (2006) The prolyl isomerase Pin1 regulates amyloid precursor protein processing and amyloid-beta production. Nature 440, 528-534.

[89] Lu KP, Kondo A, Albayram O, Herbert MK, Liu H, Zhou XZ (2016) Potential of the Antibody Against cis-Phosphorylated Tau in the Early Diagnosis, Treatment, and Prevention of Alzheimer Disease and Brain Injury. JAMA Neurol 73, 1356-1362.

[90] Lu PJ, Wulf G, Zhou XZ, Davies P, Lu KP (1999) The prolyl isomerase Pin1 restores the function of Alzheimer-associated phosphorylated tau protein. Nature 399, 784-788.

[91] Pascual-Lucas M, Viana da Silva S, Di Scala M, Garcia-Barroso C, González-Aseguinolaza G, Mulle C, Alberini CM, Cuadrado-Tejedor M, Garcia-Osta A (2014) Insulin-like growth factor 2 reverses memory and synaptic deficits in APP transgenic mice. EMBO Mol Med 6, $1246-1262$.

[92] Xie K, Liu Y, Hao W, Walter S, Penke B, Hartmann T, Schachner M, Fassbender K (2013) Tenascin-C deficiency ameliorates Alzheimer's disease-related pathology in mice. Neurobiol Aging 34, 2389-2398.

[93] Stewart CR, Stuart LM, Wilkinson K, van Gils JM, Deng J, Halle A, Rayner KJ, Boyer L, Zhong R, Frazier WA, Lacy-Hulbert A, El Khoury J, Golenbock DT, Moore KJ (2010) CD36 ligands promote sterile inflammation through assembly of a Toll-like receptor 4 and 6 heterodimer. Nat Immunol 11, 155-161.

[94] Mahaman YAR, Huang F, Kessete Afewerky H, Maibouge TMS, Ghose B, Wang X (2019) Involvement of calpain in the neuropathogenesis of Alzheimer's disease. Med Res Rev 39 , 608-630.

[95] Ferreira A (2012) Calpain dysregulation in Alzheimer's disease. ISRN Biochem 2012, 728571.

[96] Castro-Alvarez JF, Uribe-Arias SA, Kosik KS, Cardona-Gómez GP (2014) Long- and shortterm CDK5 knockdown prevents spatial memory dysfunction and tau pathology of triple transgenic Alzheimer's mice. Front Aging Neurosci 6, 243. 
[97] Zheng Y-L, Kesavapany S, Gravell M, Hamilton RS, Schubert M, Amin N, Albers W, Grant $P$, Pant HC (2005) A Cdk5 inhibitory peptide reduces tau hyperphosphorylation and apoptosis in neurons. EMBO J 24, 209-220.

[98] Liu F, Su Y, Li B, Zhou Y, Ryder J, Gonzalez-DeWhitt P, May PC, Ni B (2003) Regulation of amyloid precursor protein (APP) phosphorylation and processing by $\mathrm{p} 35 / \mathrm{Cdk} 5$ and p25/Cdk5. FEBS Lett 547, 193-196.

[99] Lopes JP, Oliveira CR, Agostinho P (2009) Cdk5 acts as a mediator of neuronal cell cycle re-entry triggered by amyloid-beta and prion peptides. Cell Cycle 8, 97-104.

[100] Li H, Ruberu K, Muñoz SS, Jenner AM, Spiro A, Zhao H, Rassart E, Sanchez D, Ganfornina MD, Karl T, Garner B (2015) Apolipoprotein D modulates amyloid pathology in APP/PS1 Alzheimer's disease mice. Neurobiol Aging 36, 1820-1833.

[101] Martínez E, Navarro A, Ordóñez C, Del Valle E, Tolivia J (2012) Amyloid- $\beta 25-35$ induces apolipoprotein D Synthesis and growth arrest in HT22 hippocampal cells. J Alzheimers Dis 30, 233-244.

[102] Lee S-J, Seo B-R, Koh J-Y (2015) Metallothionein-3 modulates the amyloid $\beta$ endocytosis of astrocytes through its effects on actin polymerization. Mol Brain 8, 84.

[103] Manso Y, Carrasco J, Comes G, Meloni G, Adlard PA, Bush AI, Vašák M, Hidalgo J (2012) Characterization of the role of metallothionein-3 in an animal model of Alzheimer's disease. Cell Mol Life Sci 69, 3683-3700.

[104] Balasubramaniam M, Ayyadevara S, Shmookler Reis RJ (2018) Structural insights into pro-aggregation effects of C. elegans CRAM-1 and its human ortholog SERF2. Sci Rep 8, 14891.

[105] van Ham TJ, Holmberg MA, van der Goot AT, Teuling E, Garcia-Arencibia M, Kim H-E, Du D, Thijssen KL, Wiersma M, Burggraaff R, van Bergeijk $P$, van Rheenen J, Jerre van Veluw G, Hofstra RMW, Rubinsztein DC, Nollen EAA (2010) Identification of MOAG4/SERF as a regulator of age-related proteotoxicity. Cell 142, 601-612.

[106] Ashby EL, Kehoe PG, Love S (2010) Kallikrein-related peptidase 6 in Alzheimer's disease and vascular dementia. Brain Res 1363, 1-10.

[107] Diamandis EP, Yousef GM, Petraki C, Soosaipillai AR (2000) Human kallikrein 6 as a biomarker of alzheimer's disease. Clin Biochem 33, 663-667.

[108] Kumar U (2005) Expression of somatostatin receptor subtypes (SSTR1-5) in Alzheimer's disease brain: an immunohistochemical analysis. Neuroscience 134, 525-538.

[109] Davies P, Katzman R, Terry RD (1980) Reduced somatostatin-like immunoreactivity in cerebral cortex from cases of Alzheimer disease and Alzheimer senile dementa. Nature 288, 279-280.

[110] Pan Y, Choy KHC, Marriott PJ, Chai SY, Scanlon MJ, Porter CJH, Short JL, Nicolazzo JA (2018) Reduced blood-brain barrier expression of fatty acid-binding protein 5 is associated with increased vulnerability of APP/PS1 mice to cognitive deficits from low omega-3 fatty acid diets. J Neurochem 144, 81-92.

[111] Pan Y, Short JL, Choy KHC, Zeng AX, Marriott PJ, Owada Y, Scanlon MJ, Porter CJH, Nicolazzo JA (2016) Fatty Acid-Binding Protein 5 at the Blood-Brain Barrier Regulates Endogenous Brain Docosahexaenoic Acid Levels and Cognitive Function. J Neurosci 36, 11755-11767.

[112] Nakanishi N, Ryan SD, Zhang X, Khan A, Holland T, Cho E-G, Huang X, Liao F-F, Xu H, Lipton SA, Tu S (2013) Synaptic protein $\alpha 1$-takusan mitigates amyloid- $\beta$-induced synaptic loss via interaction with tau and postsynaptic density-95 at postsynaptic sites. $J$ Neurosci 33, 14170-14183.

[113] Tu S, Shin Y, Zago WM, States BA, Eroshkin A, Lipton SA, Tong GG, Nakanishi N (2007) Takusan: a large gene family that regulates synaptic activity. Neuron 55, 69-85.

[114] Giannuzzi G, Siswara P, Malig M, Marques-Bonet T, NISC Comparative Sequencing 
Program, Mullikin JC, Ventura M, Eichler EE (2013) Evolutionary dynamism of the primate LRRC37 gene family. Genome Res 23, 46-59.

[115] Jun G, Ibrahim-Verbaas CA, Vronskaya M, Lambert J-C, Chung J, Naj AC, Kunkle BW, Wang L-S, Bis JC, Bellenguez C, Harold D, Lunetta KL, Destefano AL, Grenier-Boley B, Sims R, Beecham GW, Smith AV, Chouraki V, Hamilton-Nelson KL, Ikram MA, Fievet N, Denning N, Martin ER, Schmidt H, Kamatani Y, Dunstan ML, Valladares O, Laza AR, Zelenika D, Ramirez A, Foroud TM, Choi S-H, Boland A, Becker T, Kukull WA, van der Lee SJ, Pasquier F, Cruchaga C, Beekly D, Fitzpatrick AL, Hanon O, Gill M, Barber R, Gudnason V, Campion D, Love S, Bennett DA, Amin N, Berr C, Tsolaki M, Buxbaum JD, Lopez OL, Deramecourt V, Fox NC, Cantwell LB, Tárraga L, Dufouil C, Hardy J, Crane PK, Eiriksdottir G, Hannequin D, Clarke R, Evans D, Mosley TH Jr, Letenneur L, Brayne C, Maier W, De Jager P, Emilsson V, Dartigues J-F, Hampel H, Kamboh MI, de Bruijn RFAG, Tzourio C, Pastor P, Larson EB, Rotter JI, O'Donovan MC, Montine TJ, Nalls MA, Mead S, Reiman EM, Jonsson PV, Holmes C, St George-Hyslop PH, Boada M, Passmore P, Wendland JR, Schmidt R, Morgan K, Winslow AR, Powell JF, Carasquillo M, Younkin SG, Jakobsdóttir J, Kauwe JSK, Wilhelmsen KC, Rujescu D, Nöthen MM, Hofman A, Jones L, IGAP Consortium, Haines JL, Psaty BM, Van Broeckhoven C, Holmans P, Launer LJ, Mayeux R, Lathrop M, Goate AM, Escott-Price V, Seshadri S, Pericak-Vance MA, Amouyel P, Williams J, van Duijn CM, Schellenberg GD, Farrer LA (2016) A novel Alzheimer disease locus located near the gene encoding tau protein. Mol Psychiatry 21, 108-117.

[116] Chang S-H, Hwang C-S, Yin J-H, Chen S-D, Yang D-I (2015) Oncostatin M-dependent Mcl-1 induction mediated by JAK1/2-STAT1/3 and CREB contributes to bioenergetic improvements and protective effects against mitochondrial dysfunction in cortical neurons. Biochim Biophys Acta 1853, 2306-2325.

[117] Kraft AW, Hu X, Yoon H, Yan P, Xiao Q, Wang Y, Gil SC, Brown J, Wilhelmsson U, Restivo JL, Cirrito JR, Holtzman DM, Kim J, Pekny M, Lee J-M (2013) Attenuating astrocyte activation accelerates plaque pathogenesis in APP/PS1 mice. FASEB J 27, 187-198.

[118] Richter F, Meurers BH, Zhu C, Medvedeva VP, Chesselet M-F (2009) Neurons express hemoglobin alpha- and beta-chains in rat and human brains. J Comp Neurol 515, 538-547.

[119] Wu C-W, Liao P-C, Yu L, Wang S-T, Chen S-T, Wu C-M, Kuo Y-M (2004) Hemoglobin promotes Abeta oligomer formation and localizes in neurons and amyloid deposits.

Neurobiol Dis 17, 367-377.

[120] Oyama R, Yamamoto H, Titani K (2000) Glutamine synthetase, hemoglobin alpha-chain, and macrophage migration inhibitory factor binding to amyloid beta-protein: their identification in rat brain by a novel affinity chromatography and in Alzheimer's disease brain by immunoprecipitation. Biochim Biophys Acta 1479, 91-102.

[121] Ullrich S, Münch A, Neumann S, Kremmer E, Tatzelt J, Lichtenthaler SF (2010) The novel membrane protein TMEM59 modulates complex glycosylation, cell surface expression, and secretion of the amyloid precursor protein. J Biol Chem 285, 2066420674.

[122] Liu Z, Ning J, Zheng X, Meng J, Han L, Zheng H, Zhong L, Chen X-F, Zhang X, Luo H, Can D, Xu H, Zhang Y-W (2020) TMEM59 interacts with TREM2 and modulates TREM2dependent microglial activities. Cell Death Dis 11, 678.

[123] Burgos PV, Mardones GA, Rojas AL, daSilva LLP, Prabhu Y, Hurley JH, Bonifacino JS (2010) Sorting of the Alzheimer's disease amyloid precursor protein mediated by the AP-4 complex. Dev Cell 18, 425-436.

[124] Terrey M, Adamson SI, Gibson AL, Deng T, Ishimura R, Chuang JH, Ackerman SL (2020) GTPBP1 resolves paused ribosomes to maintain neuronal homeostasis. Elife 9,.

[125] Kapur M, Ganguly A, Nagy G, Adamson SI, Chuang JH, Frankel WN, Ackerman SL (2020) Expression of the Neuronal tRNA n-Tr20 Regulates Synaptic Transmission and 
Seizure Susceptibility. Neuron 108, 193-208.e9.

[126] Das Sharma S, Metz JB, Li H, Hobson BD, Hornstein N, Sulzer D, Tang G, Sims PA (2019) Widespread Alterations in Translation Elongation in the Brain of Juvenile Fmr1 Knockout Mice. Cell Rep 26, 3313-3322.e5.

[127] Hornstein N, Torres D, Das Sharma S, Tang G, Canoll P, Sims PA (2016) Ligation-free ribosome profiling of cell type-specific translation in the brain. Genome Biol 17, 149.

[128] Biever A, Glock C, Tushev G, Ciirdaeva E, Dalmay T, Langer JD, Schuman EM (2020) Monosomes actively translate synaptic mRNAs in neuronal processes. Science 367, eaay4991.

[129] Wang Y, Cella M, Mallinson K, Ulrich JD, Young KL, Robinette ML, Gilfillan S, Krishnan GM, Sudhakar S, Zinselmeyer BH, Holtzman DM, Cirrito JR, Colonna M (2015) TREM2 lipid sensing sustains the microglial response in an Alzheimer's disease model. Cell 160, $1061-1071$.

[130] Wang Y, Ulland TK, Ulrich JD, Song W, Tzaferis JA, Hole JT, Yuan P, Mahan TE, Shi Y, Gilfillan S, Cella M, Grutzendler J, DeMattos RB, Cirrito JR, Holtzman DM, Colonna M (2016) TREM2-mediated early microglial response limits diffusion and toxicity of amyloid plaques. J Exp Med 213, 667-675.

[131] Yuan P, Condello C, Keene CD, Wang Y, Bird TD, Paul SM, Luo W, Colonna M, Baddeley D, Grutzendler J (2016) TREM2 Haplodeficiency in Mice and Humans Impairs the Microglia Barrier Function Leading to Decreased Amyloid Compaction and Severe Axonal Dystrophy. Neuron 90, 724-739.

[132] Konishi H, Kiyama H (2018) Microglial TREM2/DAP12 Signaling: A Double-Edged Sword in Neural Diseases. Frontiers in Cellular Neuroscience 12, article 206.

[133] Ulland TK, Song WM, Huang SC-C, Ulrich JD, Sergushichev A, Beatty WL, Loboda AA, Zhou Y, Cairns NJ, Kambal A, Loginicheva E, Gilfillan S, Cella M, Virgin HW, Unanue ER, Wang Y, Artyomov MN, Holtzman DM, Colonna M (2017) TREM2 Maintains Microglial Metabolic Fitness in Alzheimer's Disease. Cell 170, 649-663.e13.

[134] Ryu JK, Rafalski VA, Meyer-Franke A, Adams RA, Poda SB, Rios Coronado PE, Pedersen LØ, Menon V, Baeten KM, Sikorski SL, Bedard C, Hanspers K, Bardehle S, Mendiola AS, Davalos D, Machado MR, Chan JP, Plastira I, Petersen MA, Pfaff SJ, Ang KK, Hallenbeck KK, Syme C, Hakozaki H, Ellisman MH, Swanson RA, Zamvil SS, Arkin MR, Zorn SH, Pico AR, Mucke L, Freedman SB, Stavenhagen JB, Nelson RB, Akassoglou $\mathrm{K}$ (2018) Fibrin-targeting immunotherapy protects against neuroinflammation and neurodegeneration. Nat Immunol 19, 1212-1223.

[135] Lee CYD, Daggett A, Gu X, Jiang L-L, Langfelder P, Li X, Wang N, Zhao Y, Park CS, Cooper Y, Ferando I, Mody I, Coppola G, Xu H, Yang XW (2018) Elevated TREM2 Gene Dosage Reprograms Microglia Responsivity and Ameliorates Pathological Phenotypes in Alzheimer's Disease Models. Neuron 97, 1032-1048.e5.

[136] Holt CE, Martin KC, Schuman EM (2019) Local translation in neurons: visualization and function. Nat Struct Mol Biol 26, 557-566.

[137] Holt CE, Schuman EM (2013) The central dogma decentralized: new perspectives on RNA function and local translation in neurons. Neuron 80, 648-657.

[138] Sotelo-Silveira JR, Holt CE (2014) Introduction to the special issue on local protein synthesis in axons. Dev Neurobiol 74, 207-209.

[139] Farias J, Sotelo JR, Sotelo-Silveira J (2019) Toward Axonal System Biology: Genome Wide Views of Local mRNA Translation. Proteomics 19, e1900054. 
bioRxiv preprint doi: https://doi.org/10.1101/2021.09.17.460831; this version posted September 18, 2021. The copyright holder for this preprint (which was not certified by peer review) is the author/funder, who has granted bioRxiv a license to display the preprint in perpetuity. It is made available under aCC-BY-NC-ND 4.0 International license.

\section{TABLES}

Table 1. $A D$ model mice

\begin{tabular}{|c|c|c|c|c|}
\hline Strain & Gene(s) & Mutations & Modification & $\begin{array}{c}\text { WildTtype } \\
\text { Background } \\
\text { Strain }\end{array}$ \\
\hline $\begin{array}{c}\text { CVN } \\
\left(\text { APP }_{\text {SwDI }} \mathrm{x}\right. \\
\left.\mathrm{NOS2}^{-/-}\right)\end{array}$ & $\begin{array}{l}\text { APP, } \\
\text { NOS2 }\end{array}$ & $\begin{array}{c}\text { APP: } \\
\text { K670N/M671L, } \\
\text { E693Q, D694N }\end{array}$ & $\begin{array}{c}\text { APP: Transgenic } \\
\text { NOS2: Knock- } \\
\text { Out }\end{array}$ & C57/BL6 \\
\hline $\operatorname{Tg} 2576$ & APP & APP: KM670/671NL & APP: Transgenic & B6;SJL \\
\hline
\end{tabular}

${ }^{*}$ APPSwDI x NOS2 Knock-out 
Table 2. Differentially expressed genes for CVN and Tg2576 mice versus their wild type background strain counterparts. Differentially expressed genes, defined by p-adjusted value $<0.05$, are separated by fold change $(\mathrm{FC})$ intervals.

\begin{tabular}{llcccc}
\hline \multirow{2}{*}{$\boldsymbol{C V N}$ vs $\boldsymbol{W T}$} & \multicolumn{5}{c}{$p$-adjusted value < 0.05 } \\
\cline { 2 - 6 } & & $F C>1.5$ & $F C>1$ & $F C<-1.5$ & $F C<-1$ \\
\hline \multirow{2}{*}{ edge $R$} & RNA-Seq & 160 & 282 & 80 & 187 \\
\cline { 2 - 6 } & Ribo-Seq & 300 & 830 & 77 & 335 \\
\hline \multirow{2}{*}{ Xtail } & $\begin{array}{l}\text { Translational } \\
\text { Efficiency }\end{array}$ & 88 & 491 & 56 & 306 \\
\hline
\end{tabular}

Tg2576 vs WT

$p$-adjusted value $<0.05$

\begin{tabular}{llcccc}
\cline { 2 - 5 } edge $R$ & $F C>1.5$ & $F C>1$ & $F C<-1.5$ & $F C<-1$ \\
\cline { 2 - 6 } & RNA-Seq & 76 & 194 & 64 & 149 \\
\hline \multirow{2}{*}{ Xtail } & $\begin{array}{l}\text { Translational } \\
\text { Efficiency }\end{array}$ & 25 & 50 & 25 & 69 \\
\hline
\end{tabular}




\section{FIGURE LEGENDS}

Fig. 1. Protocol summary. A) Phenotypes of the CVN (adapted from CVN - Alzforum) and Tg2576 (adapted from Tg2576 - Alzforum) mice used in this study. Three 6 month old male mice were used for each transgenic strain, and for each corresponding WT strain (C57/BI6 for CVN and B6;SJL for Tg2576). B) Sample preparation. Brain cortex was dissected and homogenized using a glass Dounce homogenizer to yield a transcriptome sample containing total RNA to be used for RNA-Seq, and a post-mitochondrial supernatant, which was ultracentrifuged to isolate polysomes. Ribosome footprints for Ribo-seq were isolated from the polysomes by an RNA protection assay that digested all RNA not encased inside the ribosomes. Further details are described in the Materials and Methods section.

Fig. 2. Differential expression in CVN versus WT (C57/Bl6) cortices determined by edge $R$ for transcriptomes $(A-C)$, and by Xtail for translational efficiency (D-F). Scatter plots comparing normalized CPM expression between genotypes for transcriptome and translational efficiency values, respectively, are shown in $(A)$ and $(D)$. Volcano plots showing the relationship between fold change and p-adjusted values are shown in (B) and (E). Scatter plots comparing translational versus transcriptional fold change are shown in $(C)$ and $(F)$.

Fig. 3. Differential expression in Tg2576 versus WT (B6;SJL) cortices determined by edge $R$ for transcriptomes $(A-C)$, and by Xtail for translational efficiency (D-F). Scatter plots comparing normalized CPM expression between genotypes for transcriptome and translational efficiency values, respectively, are shown in (A) and (D). Volcano plots showing the relationship between fold change and $p$-adjusted values are shown in $(B)$ and $(E)$. Scatter plots comparing translational versus transcriptional fold change are shown in $(C)$ and $(F)$.

Fig. 4. Heatmaps of differentially expressed genes $(F C>1.5$ and $p$-adjusted value $<0.05)$.

Fig. 5. Functional enrichment analysis of differentially expressed genes in CVN and Tg2576 mice. The top 10 (z-score) decreased and increased functional categories are shown for RNA-Seq, Ribo-Seq and Translational Efficiency. Analysis was performed using Ingenuity Pathway Analysis and graphical representation was obtained from GOplot R package. Table S4 contains the complete set of decreased and increased pathways at each level. 
Fig. 6. Upstream regulation in CVN mice predicted from differentially expressed gene lists by Ingenuity Pathway Analysis.

Fig. 7. Expression regulation of genes related to A $\beta$, APP or tau metabolism. Several gene ontology categories obtained from AmiGO2, were merged to consider all genes related to $A \beta$, APP or tau metabolism. Genes were selected by $p$-adjusted value $<0.05$ and the expression levels of those significant genes are shown on the heatmaps. 
Figure 1

A

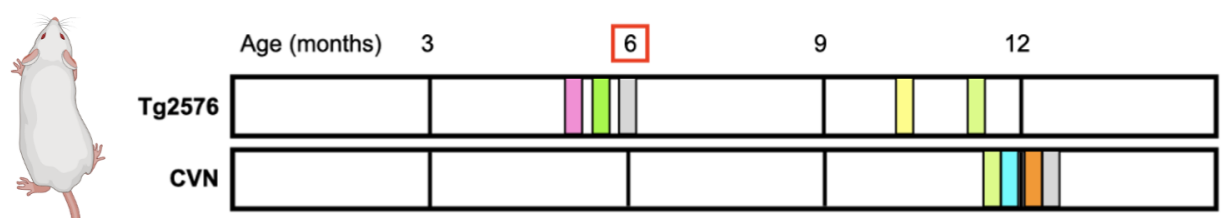

\begin{tabular}{|c|c|c|c|c|c|c|}
\hline Synapse $\downarrow$ & LTP I & Cognition $\downarrow$ & Gliosis & Plaques & Tangles & Neuron Death \\
\hline
\end{tabular}

$\sigma^{\prime n} n=3$

B

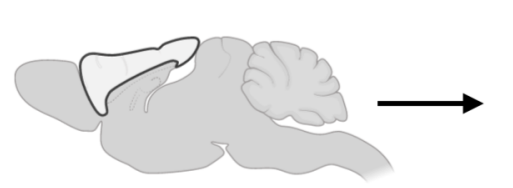

Brain cortex
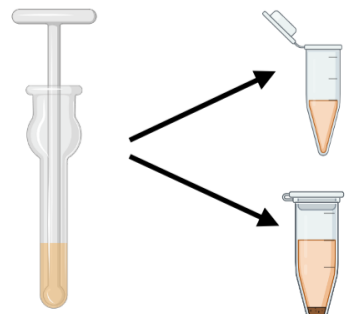

Supernatant

Transcriptome

Sample

Post Mitochondrial

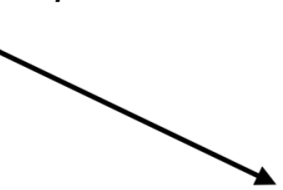

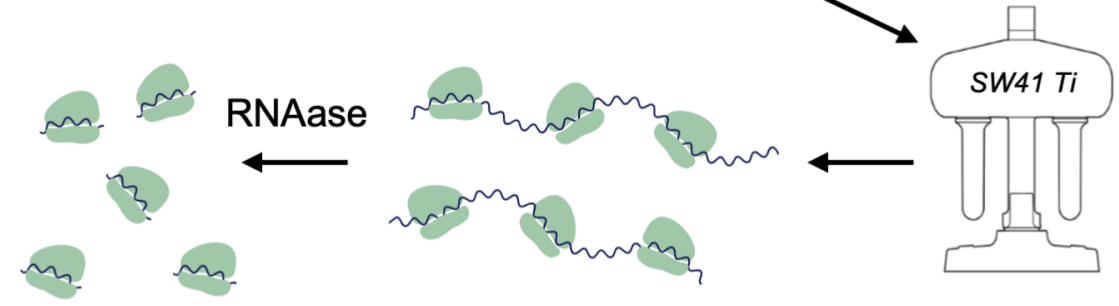

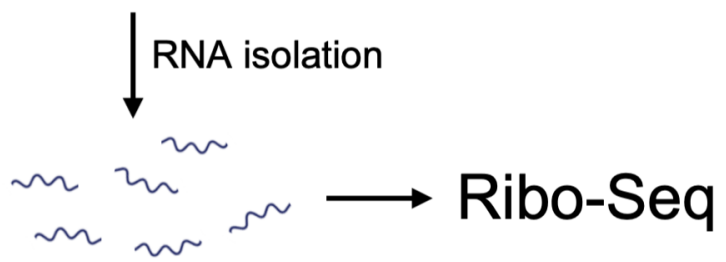

Ribosome

Footprints 
Figure 4

Transcriptomes

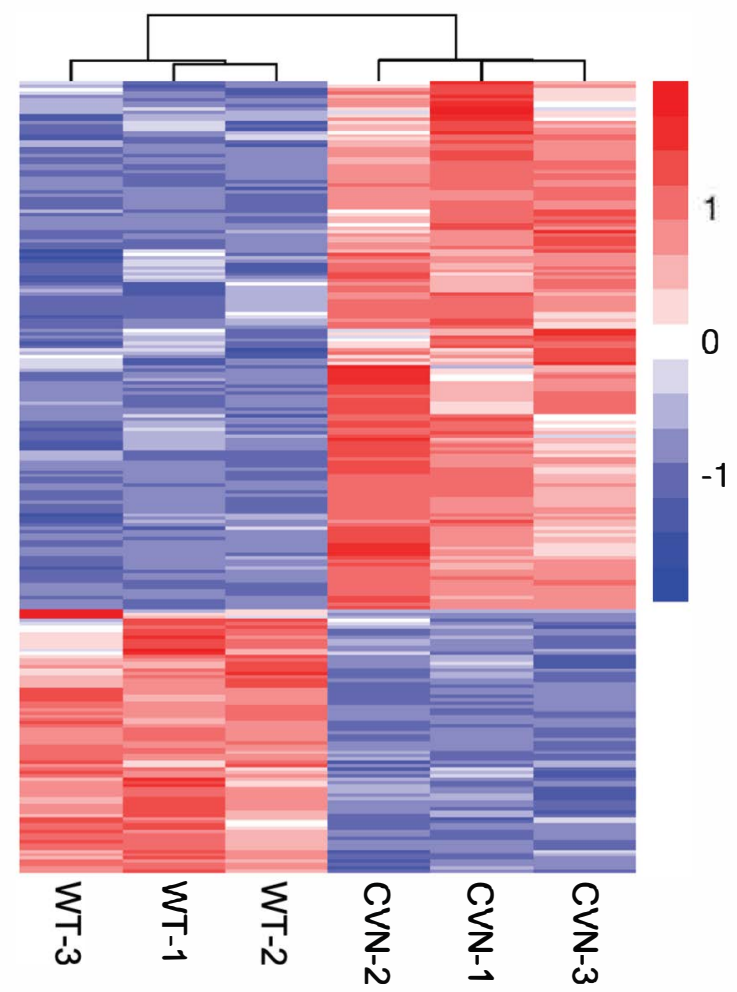

Translational Efficiencies

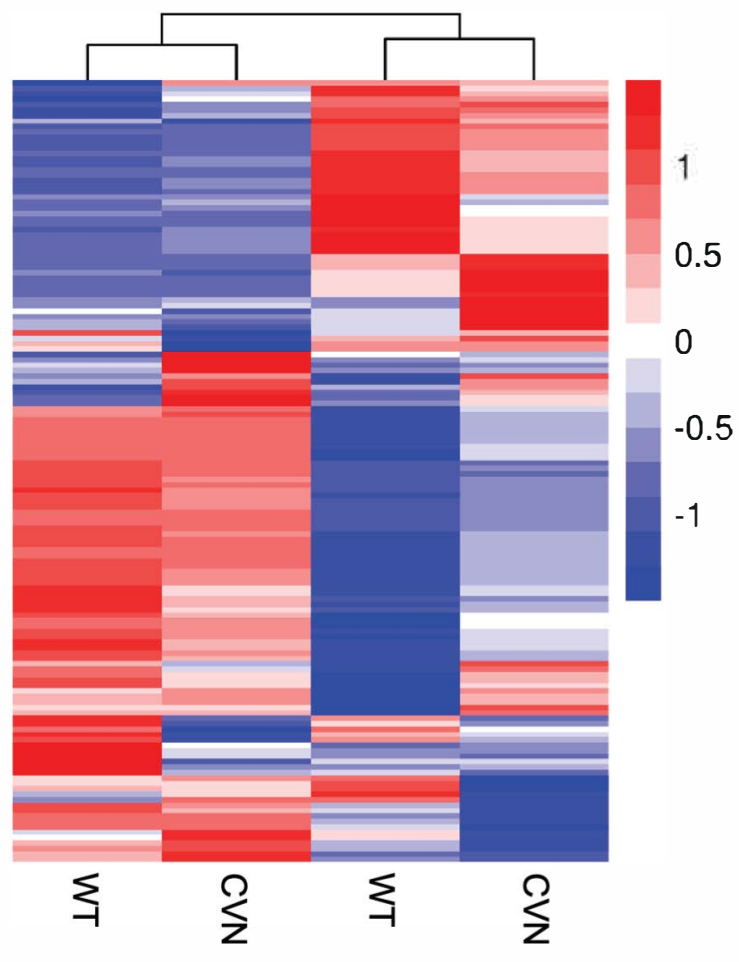

Transcriptome Translatome
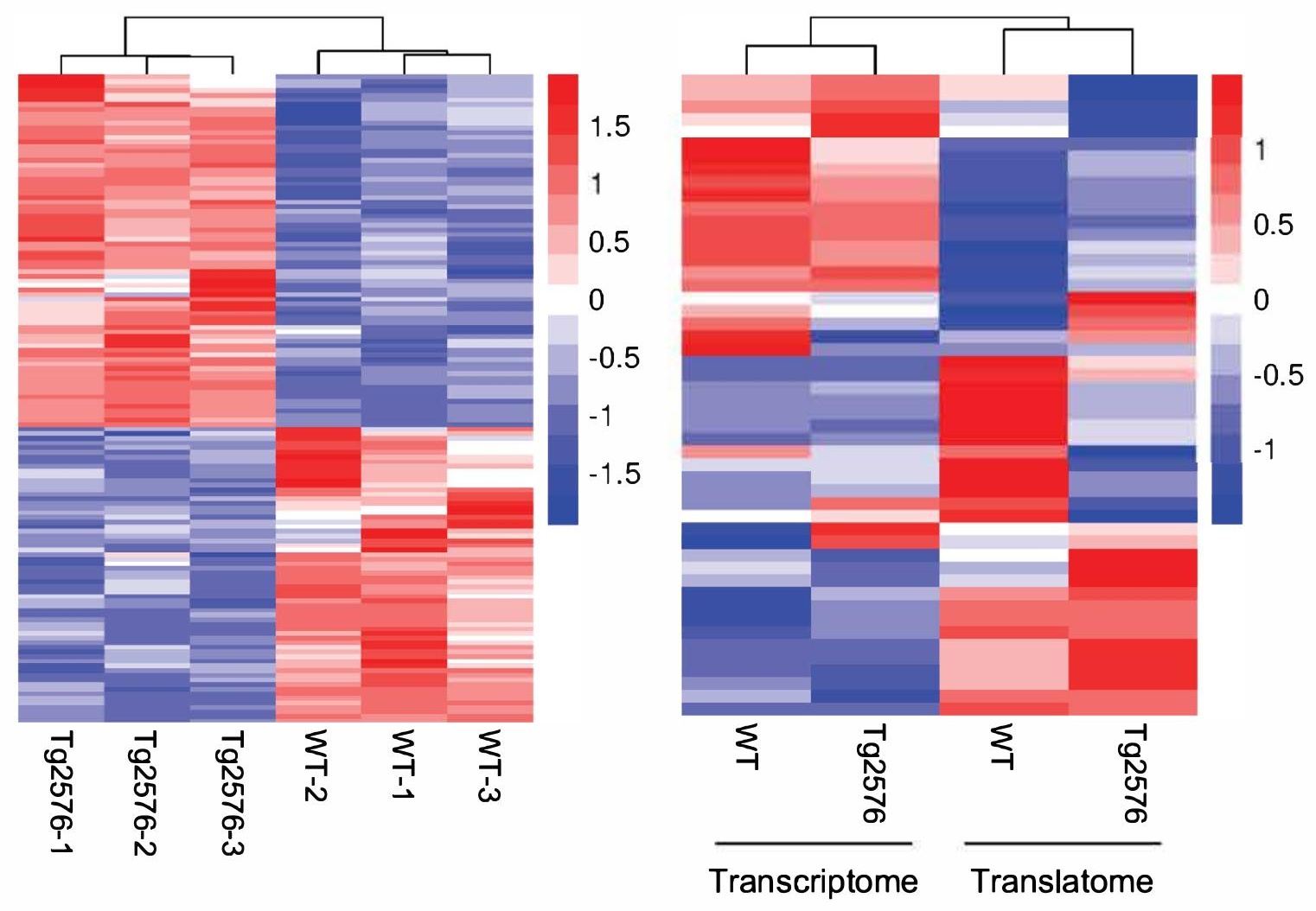


\section{Figure 5}

\section{CVN}

RNA-Seq

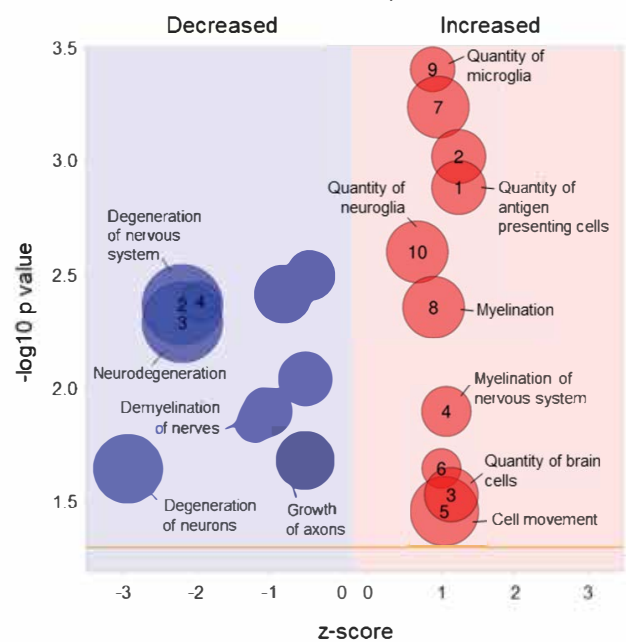

\section{$\operatorname{Tg} 2576$}

RNA-Seq
Increased

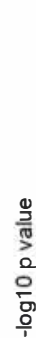

\section{Decreased}

4.0

$\frac{0}{3}$
$\frac{3}{3}$
0
0
$\frac{0}{0}$
음

2.0
Ribo-Seq

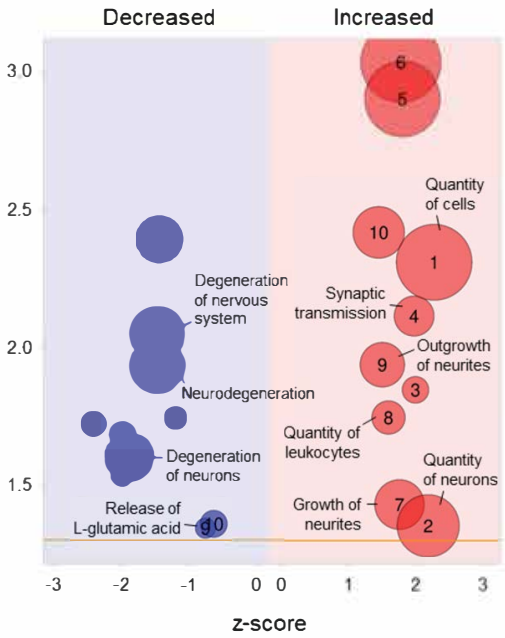

Ribo-Seq

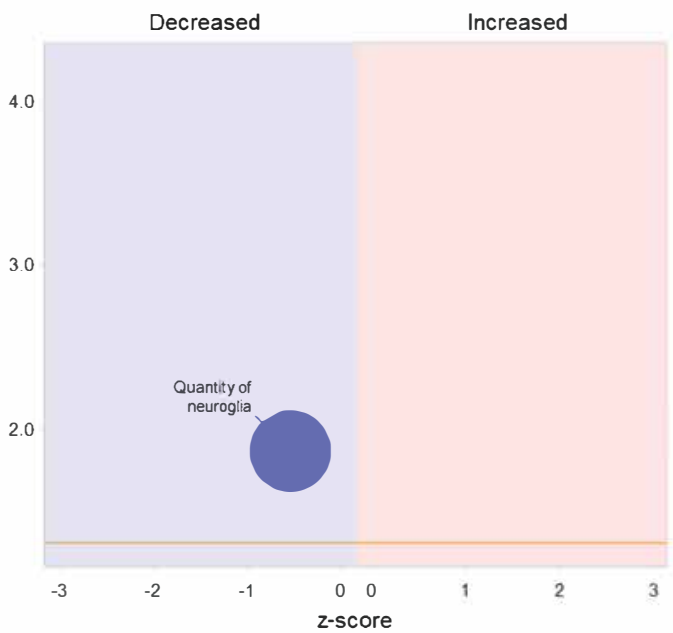

Translational Efficiency

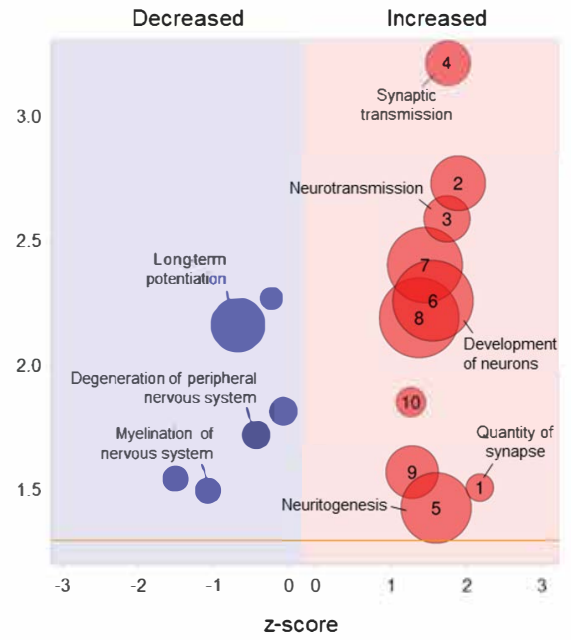

z-score 
Figure 6
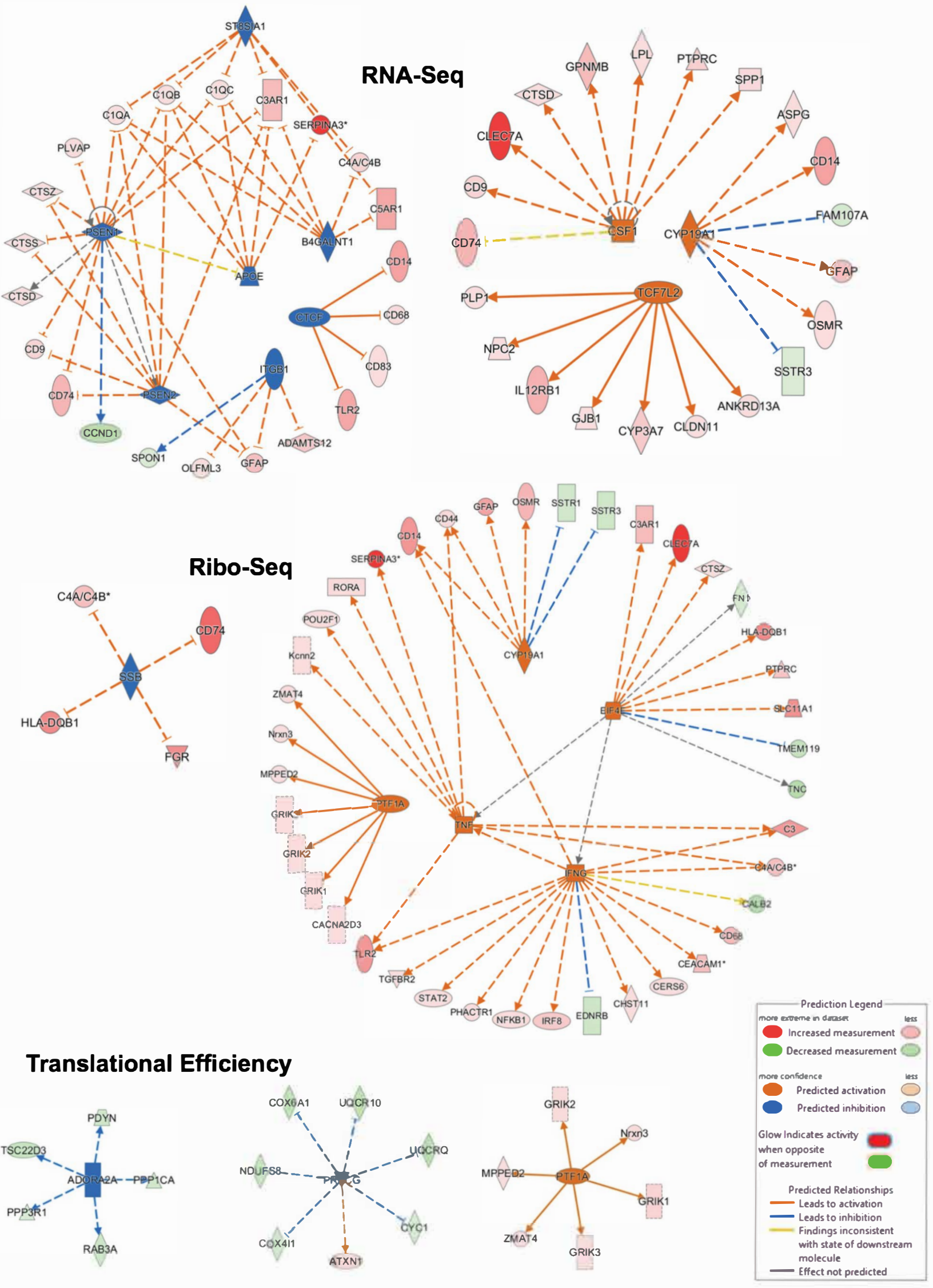


\section{SUPPLEMENTARY MATERIAL}

Table S1. The number of sequenced and mapped reads is shown for each mouse strain for both transcriptome and translatome samples.

\section{Transcriptome (RNA-Seq)}

\begin{tabular}{|c|c|c|c|c|c|c|c|c|}
\hline \multirow{3}{*}{ Genotype } & \multirow{3}{*}{$\begin{array}{l}\# \\
1\end{array}$} & \multirow{3}{*}{$\begin{array}{c}\text { Total } \\
\text { Sequenced } \\
\text { Reads }\end{array}$} & \multicolumn{6}{|c|}{ Mapped Reads vs } \\
\hline & & & \multicolumn{2}{|c|}{ Genome } & \multicolumn{2}{|c|}{ Genes } & \multicolumn{2}{|c|}{$m R N A s$} \\
\hline & & & $41,125,296$ & $88.9 \%$ & $36,855,454$ & $89.6 \%$ & $31,934,134$ & $77.7 \%$ \\
\hline \multirow[t]{2}{*}{ CVN } & 2 & $45,995,066$ & $40,757,997$ & $88.6 \%$ & $36,571,542$ & $89.7 \%$ & $31,583,039$ & $77.5 \%$ \\
\hline & 3 & $46,073,508$ & $40,062,186$ & $87.0 \%$ & $36,006,497$ & $89.9 \%$ & $30,657,313$ & $76.5 \%$ \\
\hline \multirow{3}{*}{$\begin{array}{c}\text { WT } \\
\text { (C57/BI6) }\end{array}$} & 1 & $46,527,924$ & $41,333,963$ & $88.8 \%$ & $37,089,239$ & $89.7 \%$ & $31,856,021$ & $77.1 \%$ \\
\hline & 2 & $46,984,842$ & $41,857,860$ & $89.1 \%$ & $37,628,971$ & $89.9 \%$ & $32,376,097$ & $77.3 \%$ \\
\hline & 3 & $47,219,496$ & $41,675,072$ & $88.3 \%$ & $37,445,618$ & $89.9 \%$ & $32,253,440$ & $77.4 \%$ \\
\hline \multirow{3}{*}{$\operatorname{Tg} 2576$} & 1 & $47,900,148$ & $42,341,020$ & $88.4 \%$ & $37,931,132$ & $89.6 \%$ & $32,346,342$ & $76.4 \%$ \\
\hline & 2 & $47,313,148$ & $41,749,671$ & $88.2 \%$ & $37,456,950$ & $89.7 \%$ & $32,233,304$ & $77.2 \%$ \\
\hline & 3 & $46,862,086$ & $41,510,023$ & $88.6 \%$ & $37,346,615$ & $90.0 \%$ & $31,390,282$ & $75.6 \%$ \\
\hline \multirow{3}{*}{$\begin{array}{c}\text { WT } \\
\text { (B6;6JL) }\end{array}$} & 1 & $42,170,064$ & $36,418,923$ & $86.4 \%$ & $32,647,797$ & $89.6 \%$ & $27,935,114$ & $76.7 \%$ \\
\hline & 2 & $45,516,056$ & $39,631,356$ & $87.1 \%$ & $35,511,353$ & $89.6 \%$ & $31,077,379$ & $78.4 \%$ \\
\hline & 3 & $46,065,520$ & $40,676,759$ & $88.3 \%$ & $36,505,692$ & $89.7 \%$ & $31,337,466$ & $77.0 \%$ \\
\hline
\end{tabular}

\section{Translatome (Ribo-Seq)}

\begin{tabular}{|c|c|c|c|c|c|c|c|c|c|c|}
\hline \multirow{3}{*}{ Genotype } & \multirow{3}{*}{$\begin{array}{l}\# \\
1 \\
\end{array}$} & \multirow{3}{*}{$\begin{array}{c}\text { Total } \\
\begin{array}{c}\text { Sequenced } \\
\text { Reads }\end{array} \\
125,158,118 \\
\end{array}$} & \multirow{2}{*}{\multicolumn{2}{|c|}{ non $r R N A$}} & \multicolumn{6}{|c|}{ Mapped Reads vs } \\
\hline & & & & & \multicolumn{2}{|c|}{ Genome } & \multicolumn{2}{|c|}{ Genes } & \multicolumn{2}{|c|}{$m R N A s$} \\
\hline & & & $18,467,165$ & $14.8 \%$ & $15,334,257$ & $83.0 \%$ & $12,885,534$ & $84.0 \%$ & $11,817,046$ & $77.1 \%$ \\
\hline \multirow[t]{2}{*}{ CVN } & 2 & $124,834,868$ & $19,343,288$ & $15.5 \%$ & $15,829,086$ & $81.8 \%$ & $13,623,963$ & $86.1 \%$ & $12,333,505$ & $77.9 \%$ \\
\hline & 3 & $124,796,265$ & $21,304,049$ & $17.1 \%$ & $16,367,510$ & $76.8 \%$ & $13,253,986$ & $81.0 \%$ & $12,138,772$ & $74.2 \%$ \\
\hline \multirow{3}{*}{$\begin{array}{c}\text { WT } \\
(\mathrm{C} 57 / \mathrm{Bl} 6)\end{array}$} & 1 & $125,600,184$ & $16,312,016$ & $13.0 \%$ & $13,403,450$ & $82.2 \%$ & $11,447,979$ & $85.4 \%$ & $10,303,253$ & $76.9 \%$ \\
\hline & 2 & $147,633,148$ & $19,439,215$ & $13.2 \%$ & $15,781,575$ & $81.2 \%$ & $13,555,389$ & $85.9 \%$ & $12,055,087$ & $76.4 \%$ \\
\hline & 3 & $98,153,015$ & $12,829,605$ & $13.1 \%$ & $10,372,212$ & $80.8 \%$ & $8,896,089$ & $85.8 \%$ & $8,050,517$ & $77.6 \%$ \\
\hline \multirow{2}{*}{$\operatorname{Tg} 2576$} & 1 & $124,934,216$ & $16,796,957$ & $13.4 \%$ & $13,619,869$ & $81.1 \%$ & $11,866,137$ & $87.1 \%$ & $10,695,295$ & $78.5 \%$ \\
\hline & 2 & $125,030,269$ & $18,376,892$ & $14.7 \%$ & $15,097,756$ & $82.2 \%$ & $12,872,033$ & $85.3 \%$ & $11,626,486$ & $77.0 \%$ \\
\hline
\end{tabular}


Table S2. Differentially expressed genes for CVN mice.

(Excel file attached)

Table S3. Differentially expressed genes for Tg2576 mice.

(Excel file attached)

Table S4. Complete set of decreased and increased pathway for both transgenic mice at the transcriptome, translatome and translational efficiency level determined by IPA.

(Excel file attached) 


\section{SUPPLEMENTARY FIGURE LEGENDS}

Fig. S1. Ribosome footprint purification. A) Polysome fractions digested with Benzonase were separated in a 15\% PAGE with 7M Urea. Using RNA oligos as markers, ribosome footprints bands were identified and excised in a dark room under UV light. B) Ribosome footprint quality was evaluated in a 2100 Agilent Bioanalyzer instrument using a Small RNA kit. Representative electropherograms of an unpurified polysome digestion sample and a purified ribosome footprint sample are shown.

Fig. S2. Genes detected by transcriptome (RNA-Seq) and translatome (Ribo-Seq) analysis.

Fig. S3. Inter-replicate correlations among transcriptome and translatome samples. Pearson correlation value is shown for each pairwise correlation.

Fig S4. Observed-to-expected ratio of the Ribo-Seq and RNA-Seq derived reads mapping to each of the three nucleotides in codons. Ribo-Seq derived reads 5' ends are preferentially enriched at the first nucleotide of the codon, while RNA-Seq derived reads 5' end are distributed more equally among the three nucleotides. This analysis was performed following the criteria described by Ingolia et al. Science 2009 and Guo et al. Nature 2010.

Fig. S5. Distribution of mapped reads among coding sequences (CDS), and 5' and 3' untranslated regions (5'-UTR and 3'-UTR). A) Fraction of mapped reads among mRNA features is shown for CVN and Tg2576 transgenic mice models and their wild type controls, for the Ribo-Seq and RNASeq data sets. Ribo-Seq derived reads map preferentially over CDS and RNA-Seq derived reads are distributed in a more uniform pattern. B) This difference is not due to a bias in feature length.

Fig. S6. Principal Component Analysis (PCA) for transcriptomes and translatomes. In each case, a 2D plot of principal component 1 and 2 for transcriptomes or translatomes is shown with the scree plots indicating the percentage of explained variation by each dimension of the PCA.

Fig. S7. Differential expression analysis performed by edgeR for the translatome compartment comparing CVN mice versus their WT parental strain (C57/BI6). A) Scatter plot comparing normalized CPM expressions at the translational level between genotypes. B) Volcano plot of the 
relationship between $\mathrm{FC}$ and p-adjusted values. C) Scatter plot comparing translational vs transcriptional FC, highlighting translationally regulated genes. D) Heatmap of differentially expressed genes (FC $>1.5$ and $p$-adjusted value $<0.05$ ) at the translational level.

Fig. S8. Differential expression analysis performed by edge $R$ for the translatome comparing Tg2576 mice versus their WT parental strain (B6;SJL). A) Scatter plot comparing normalized CPM expressions at the translational level between genotypes. B) Volcano plot of the relationship between FC and p-adjusted values. C) Scatter plot comparing translational vs transcriptional FC, highlighting translationally regulated genes. D) Heatmap of differentially expressed genes (FC $>1.5$ and $p$-adjusted value $<0.05$ ) at the translational level.

Fig. S9. Intersection between differentially expressed genes at transcriptome (RNA-Seq), translatome (Ribo-Seq) and translational efficiency (TE) levels for CVN and Tg2576 mice.

Fig. S10. Modulated pathways in CVN mice. Regulated pathways showed in Figure 5 are reconstructed here showing affected genes and their relationship.

Fig. S11. STRING network analysis for transcriptionally up-regulated genes (160 genes at FC $>1.5$ and $p$-adjusted value $<0.05$ ) in CVN mice. This network has significantly more interactions than expected (296 vs 53; p-adjusted value <1.0E-16). Red nodes are associated with immune system process (FDR $=2.67 \mathrm{E}-07$ ). Disconnected nodes are hidden and line thickness indicates the strength of data support.

Fig. S12. STRING network analysis for translationally up-regulated genes (300 genes at FC >1.5 and $p$-adjusted value $<0.05)$ in CVN mice. Network has significantly more interactions than expected (431 vs 164; $p<1.0 \mathrm{E}-16$ ). Red nodes are associated with the immune system processes $(F D R=3.44 E-07)$. Disconnected nodes are hidden and line thickness indicates the strength of data support.

Fig. S13. Differential expression analysis performed by edgeR for the transcriptome compartment comparing WT strains. A) Principal component analysis. B) Scatter plot comparing normalized CPM expressions at the transcriptome level between genotypes. C) Volcano plot showing the 
relationship between FC and p-adjusted values. D) Functional enrichment analysis of differentially expressed genes performed by $g$ :GOSt from g:Profiler.

Fig. S14. Differential expression analysis performed by edge $R$ for the translatome compartment comparing WT strains. A) Principal component analysis. B) Scatter plot comparing normalized CPM expressions at the translatome level between genotypes. C) Volcano plot showing the relationship between FC and p-adjusted values. D) Functional enrichment analysis of differentially expressed genes performed by $g$ :GOSt from g:Profiler.

Fig. S15. Gene expression regulation of TYRO protein kinase-binding protein (TYROBP) related immune response in CVN microglial cells. Pathway with direct and indirect causal inputs upstream and downstream of TYROBP was obtained from WikiPathways, reconstructed from Zhang B. et al. Cell (2013) and Ryu JK. et al. Nat Immunol (2018). Up-regulated genes at p-adjusted value $<0.1$ for transcriptome or translatome data sets are indicated, but no significant down-regulated genes were found. 

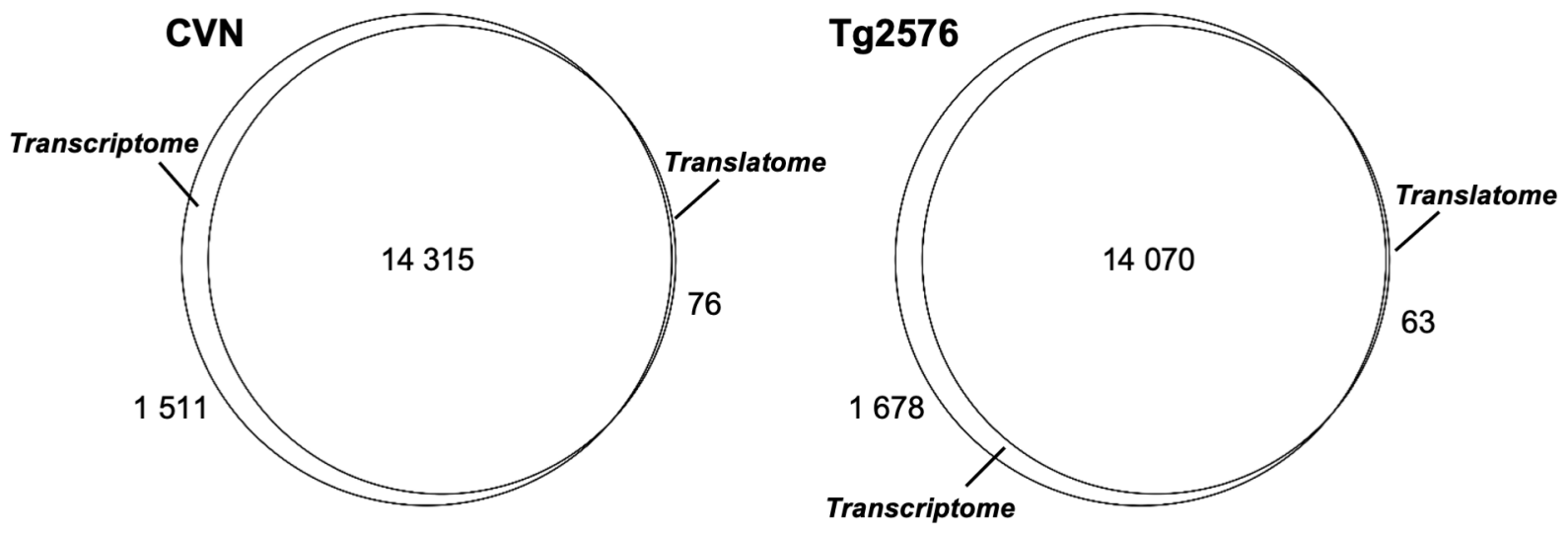

Fig. S2. Genes detected by transcriptome (RNA-Seq) and translatome (Ribo-Seq) analysis. 


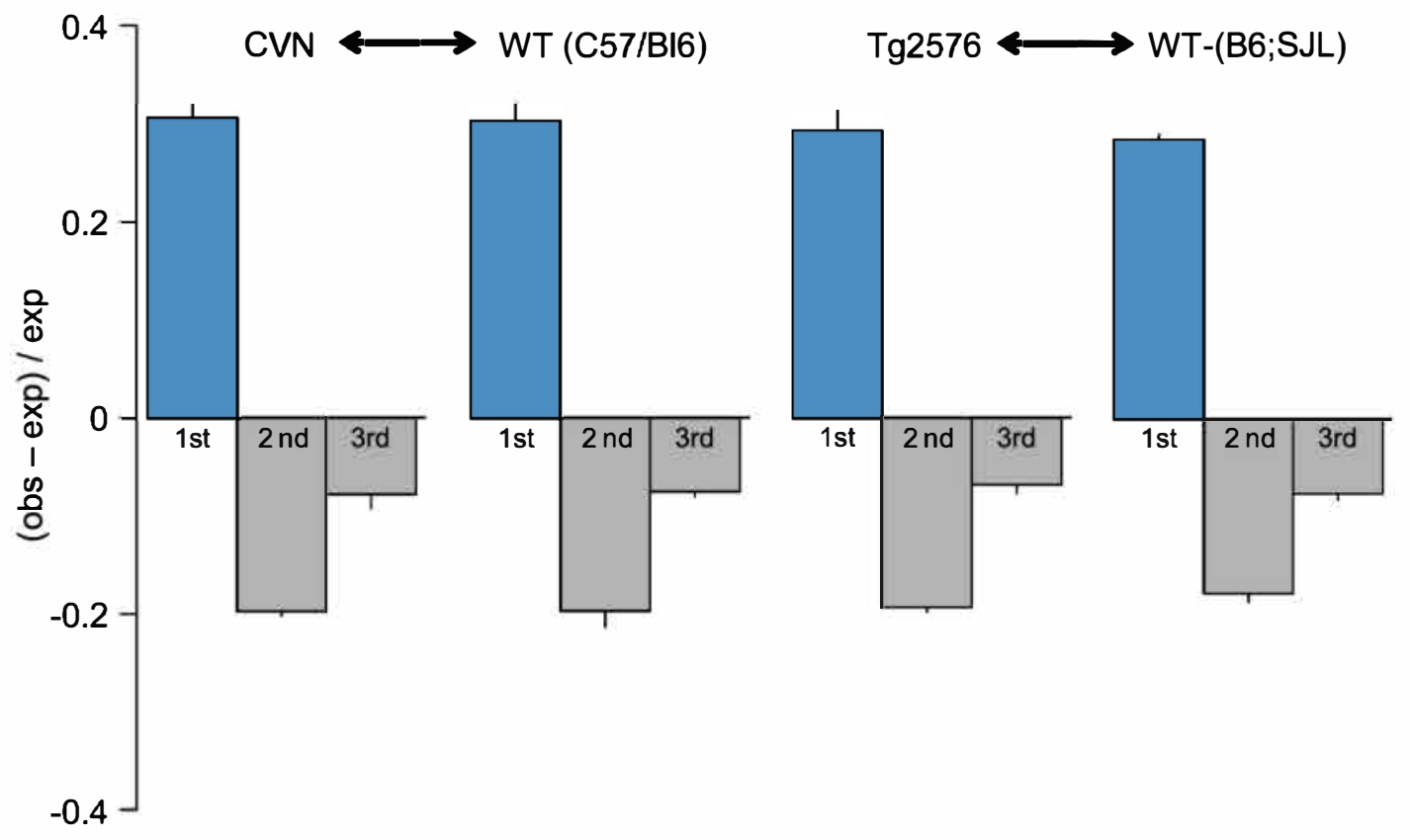

\section{RNA-Seq}

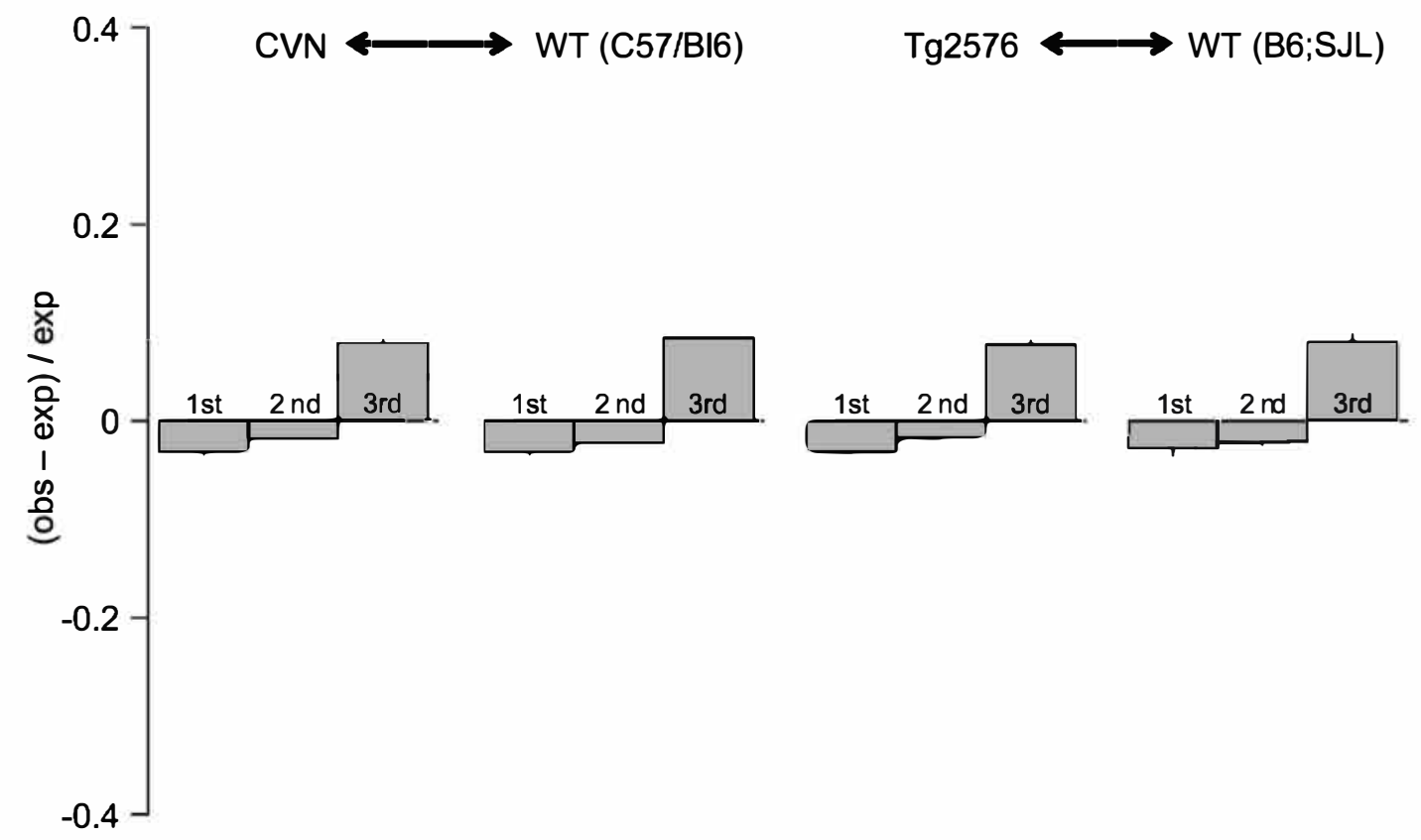

Fig. S4. Observed-to-expected ratio of the Ribo-Seq and RNA-Seq derived reads mapping to each of the three nucleotides in codons. Ribo-Seq derived reads 5' ends are preferentially enriched at the first nucleotide of the codon, while RNA-Seq derived reads 5 ' end are distributed more equally among the three nucleotides. This analysis was performed following the criteria described by Ingolia et al. Science 2009 and Guo et al. Nature 2010. 
bioRxiv preprint dA: https://doi.org/10.1101/2021.09.17.460831; this version po\$ted September 18, 2021. The copyright holder for this $p$ (which was not certified by peer review) is the author/funder, who has granted bioBxila license to display the preprint in perpetuity. It is available under aCC-BY-NC-ND 4.0 nternational license.
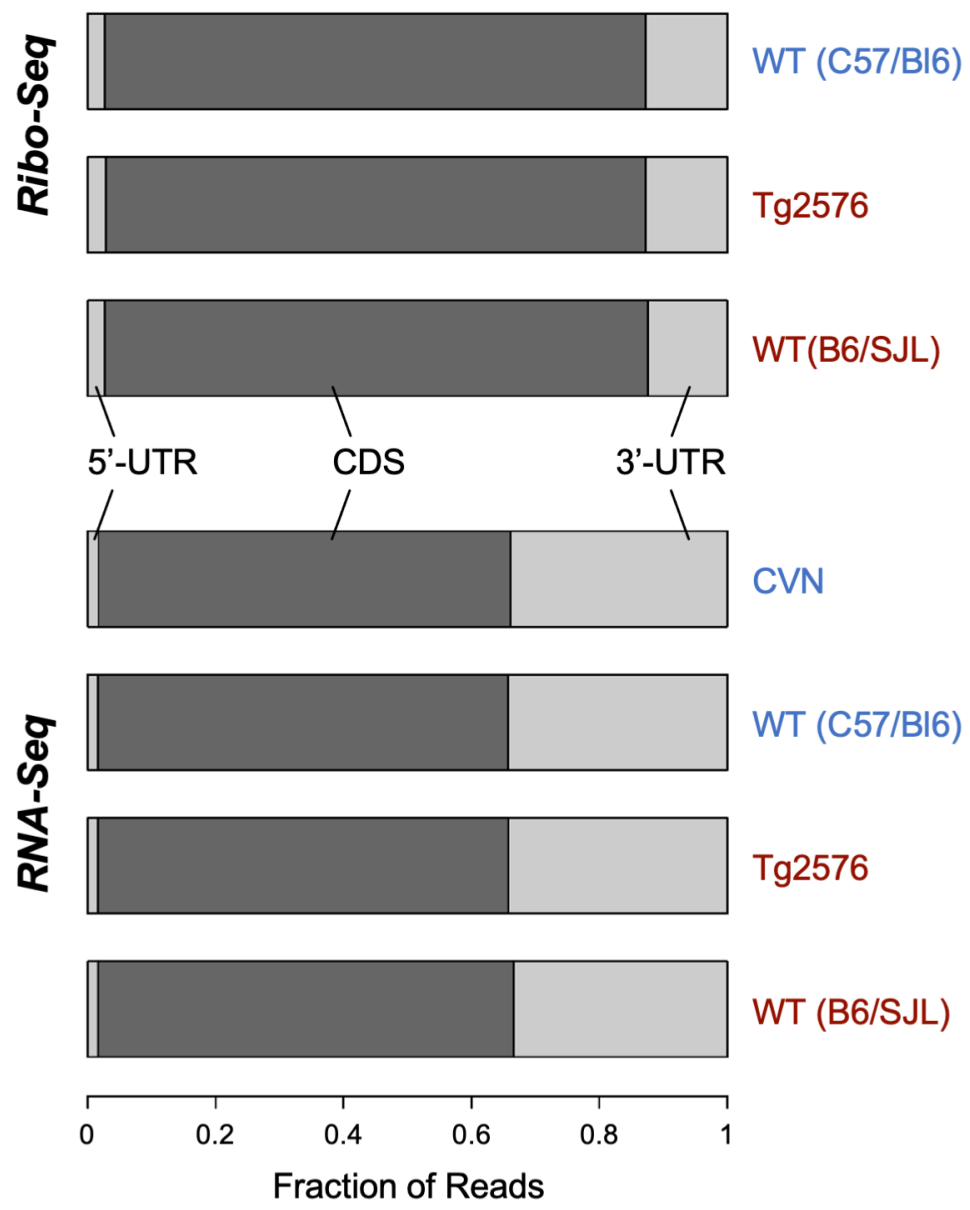

WT (B6/SJL)

B

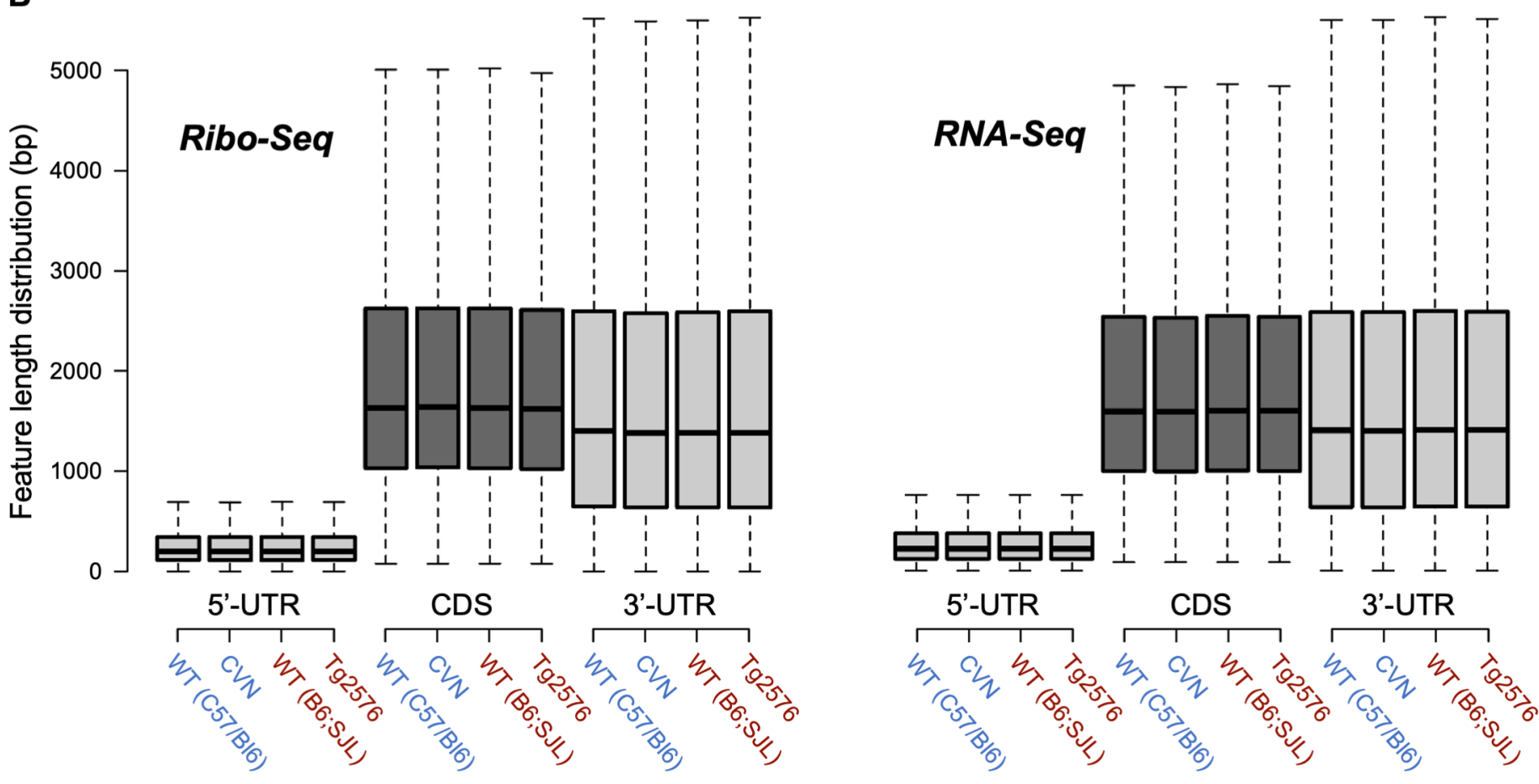

Fig. S5. Distribution of mapped reads among coding sequences (CDS), and 5' and 3' untranslated regions (5'-UTR and 3'-UTR). A) Fraction of mapped reads among mRNA's features is shown for CVN and Tg2576 transgenic mice models and their wild type controls, for the Ribo-Seq and RNA-Seq data sets. Ribo-Seq derived reads map preferentially over CDS and RNA-Seq derived reads are distributed in a more uniform pattern. B) This difference is not due to a bias in feature length. 

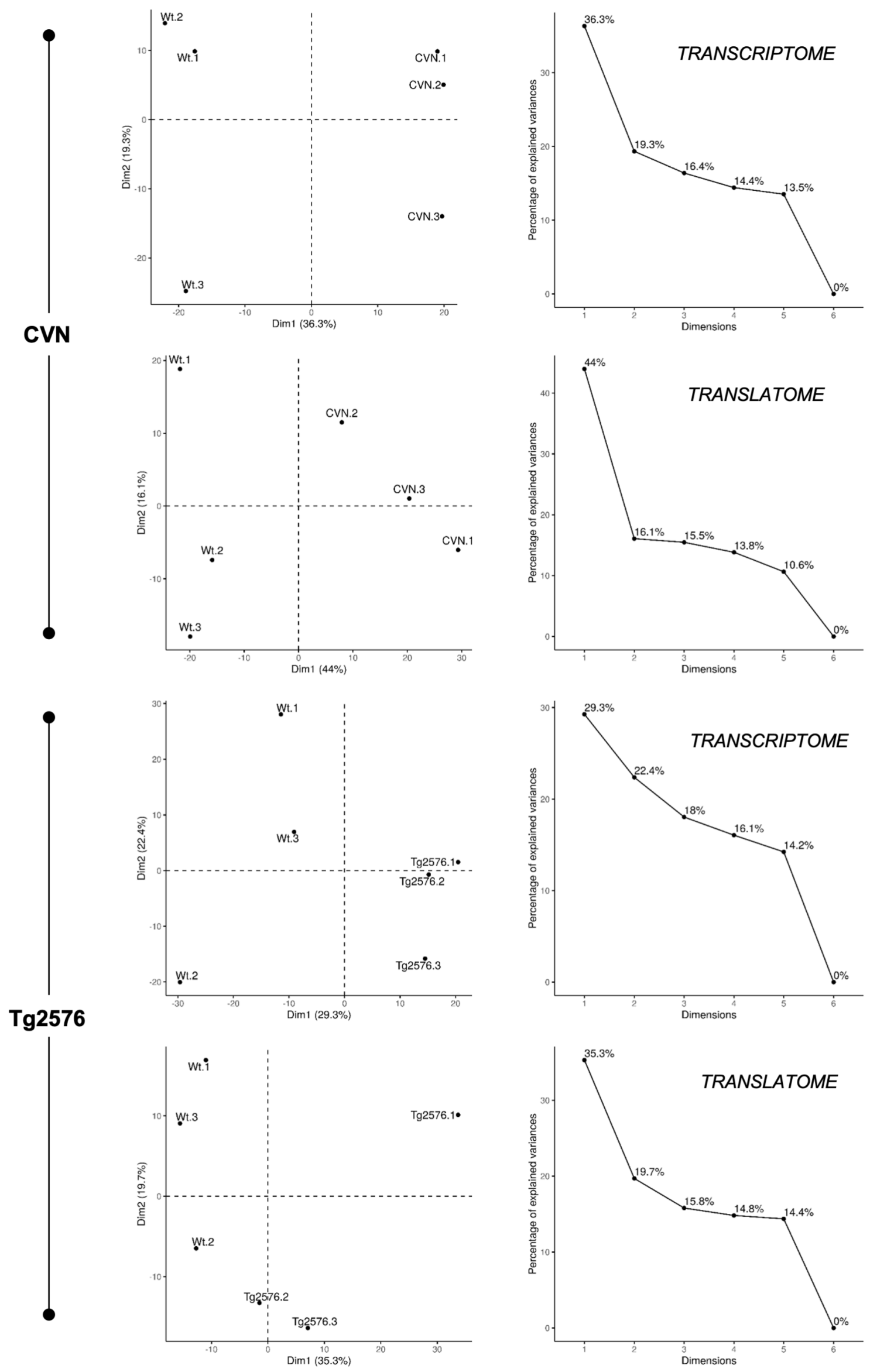

Fig. S6. Principal Component Analysis (PCA) for transcriptomes and translatomes. In each case, a 2D plot of principal component 1 and 2 for transcriptomes or translatomes is shown with the scree plots indicating the percentage of explained variation by each dimension of the PCA. 

CVN up-regulated

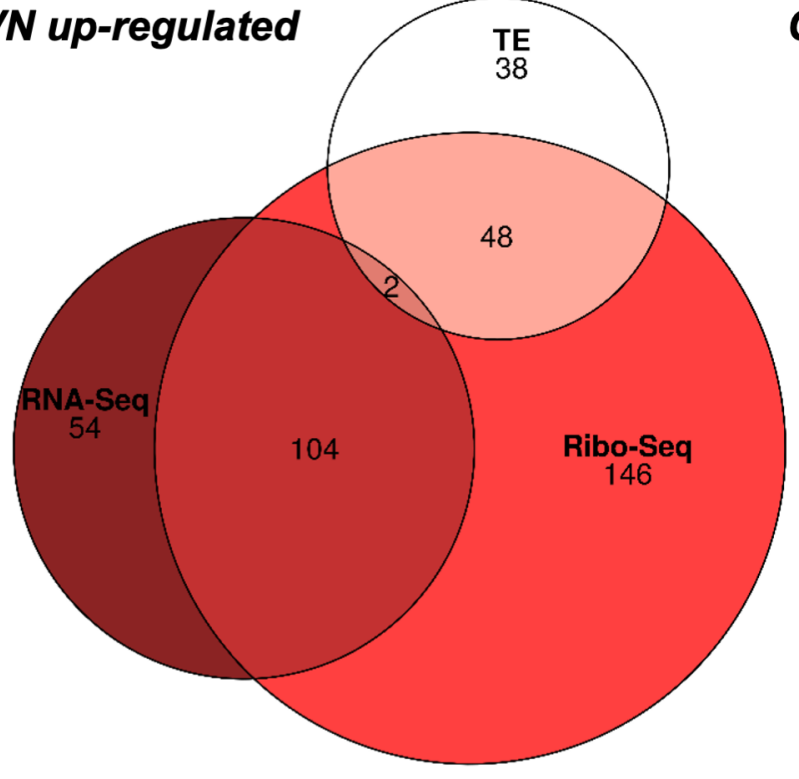

\section{Tg2576 up-regulated}

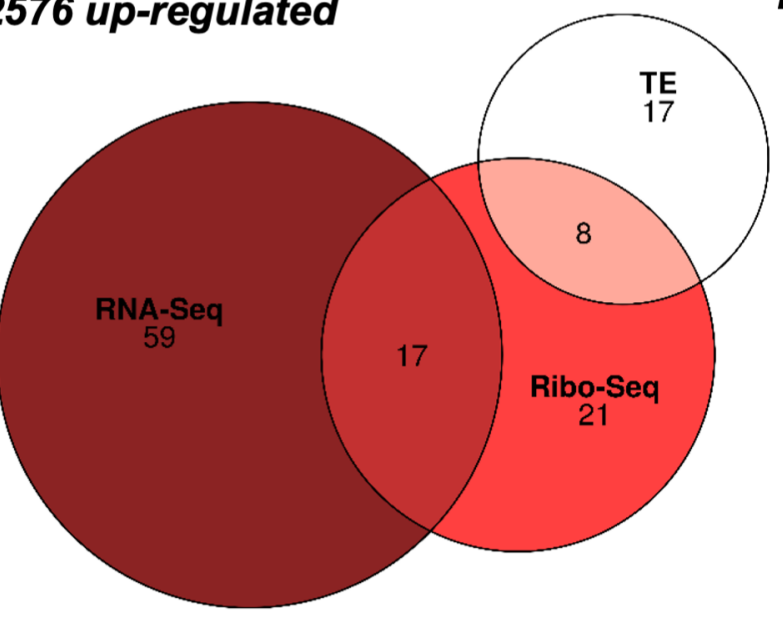

CVN down-regulated

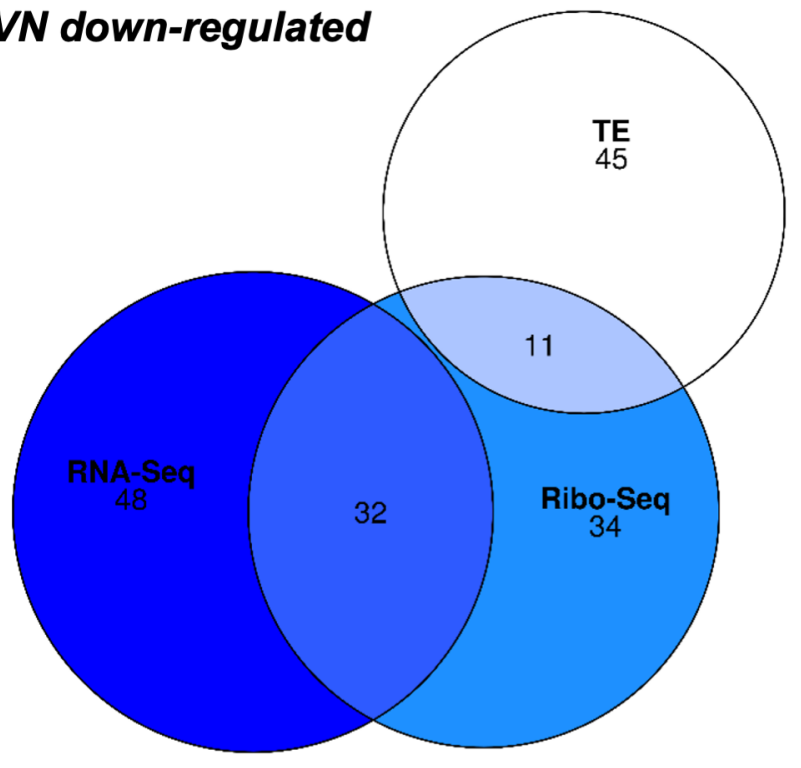

Tg2576 down-regulated

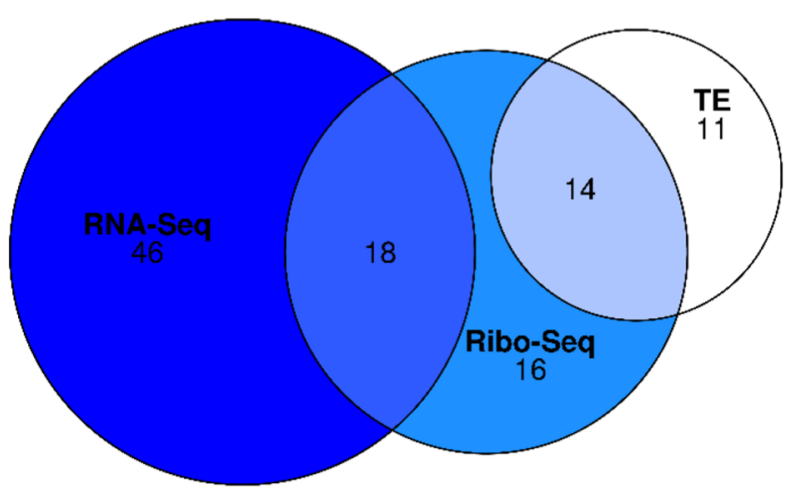

Fig. S9. Intersection between differentially expressed genes at transcriptome (RNA-Seq), translatome (Ribo-Seq) and translational efficiency (TE) levels for CVN and Tg2576 transgenic models. 


\section{CVN transcriptome}

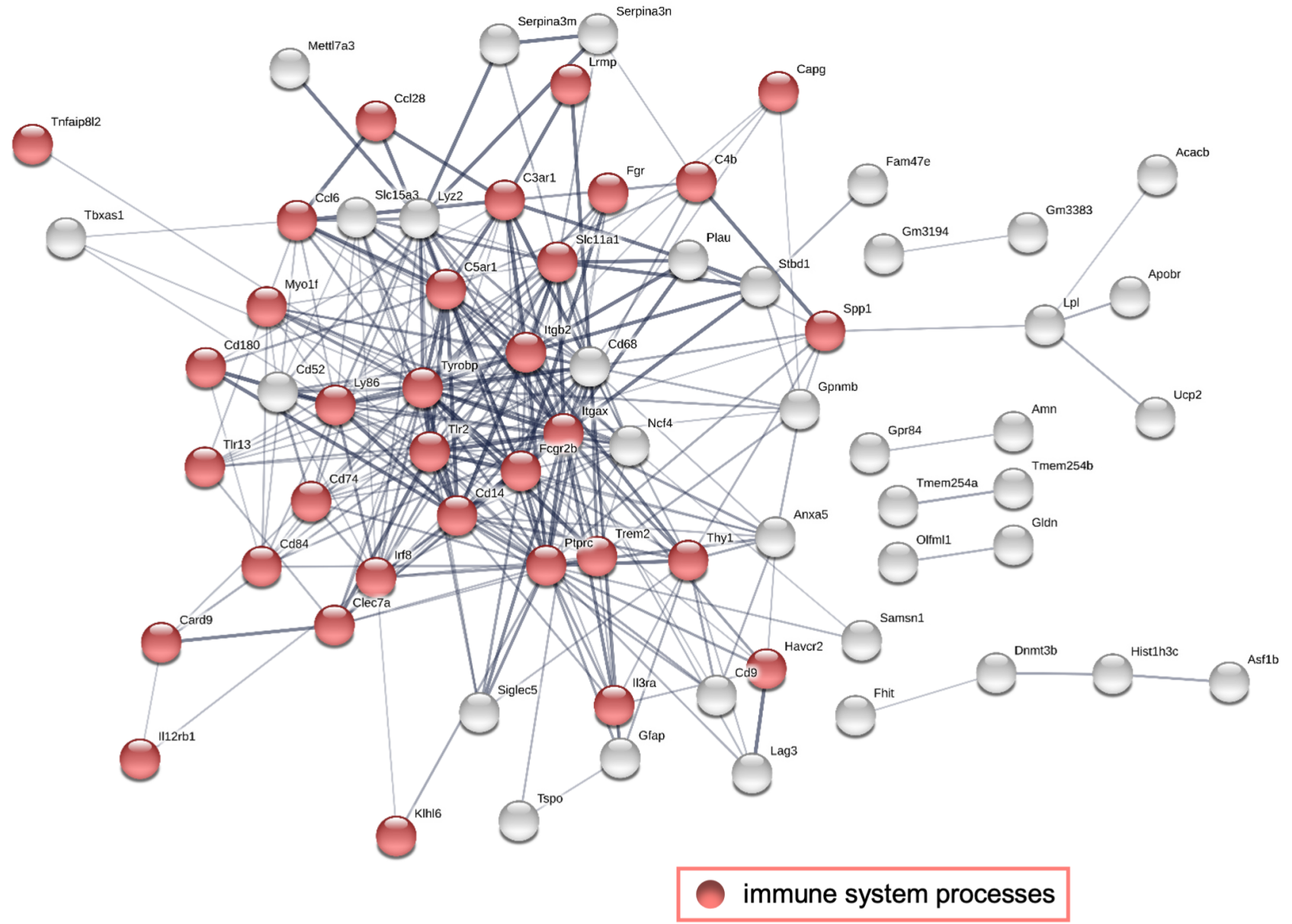

Fig. S11. STRING network analysis for transcriptionally up-regulated genes (160 genes at FC $>1.5$ and p-adjusted value $<0.05$ ) in CVN mice. This network has significantly more interactions than expected (296 vs 53; p-adjusted value $<1.0 \mathrm{E}-16$ ). Red nodes are associated with immune system process $(F D R=2.67 E-07)$. Disconnected nodes are hidden and line thickness indicates the strength of data support. 


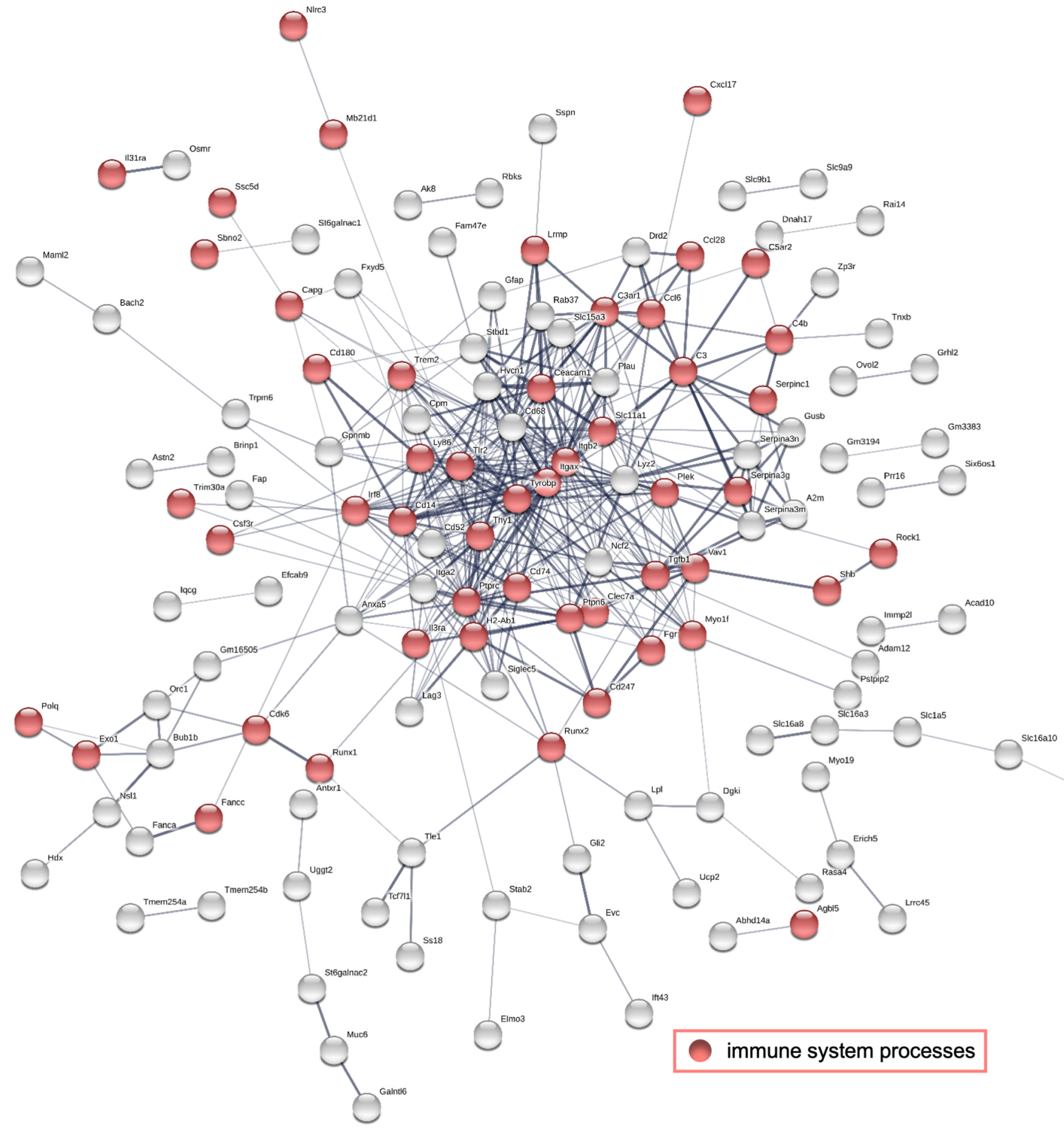

Fig. S12. STRING network analysis for translationally up-regulated genes (300 genes at FC >1.5 and padjusted value $<0.05$ ) in CVN mice. Network has significantly more interactions than expected (431 vs 164 ; $\mathrm{p}<1.0 \mathrm{E}-16$ ). Red nodes are associated with the immune system processes (FDR $=3.44 \mathrm{E}-07$ ). Disconnected nodes are hidden and line thickness indicates the strength of data support. 


\section{WT (C57/BI6) versus WT (B6;SJL) Transcriptome}

A

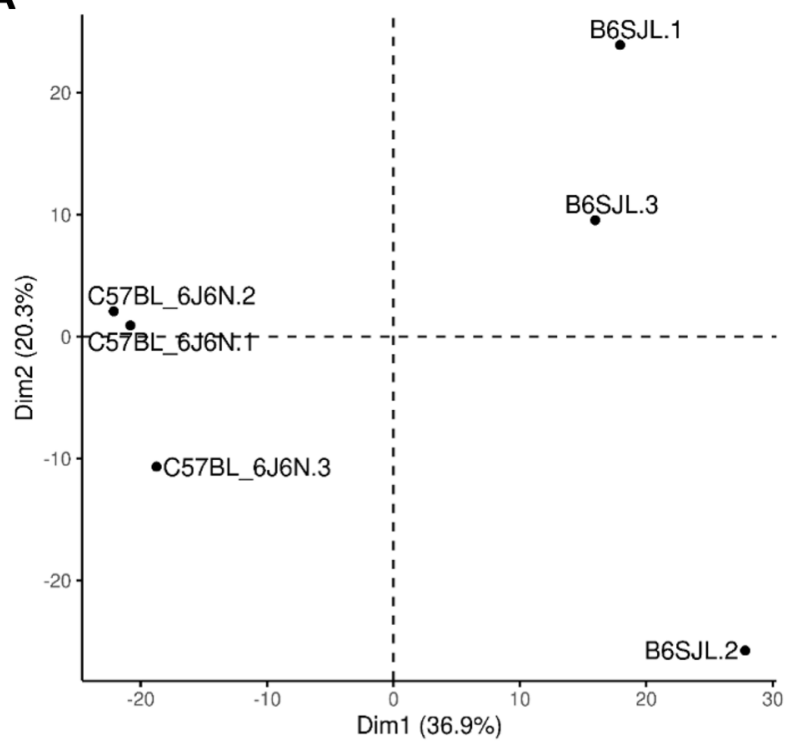

C

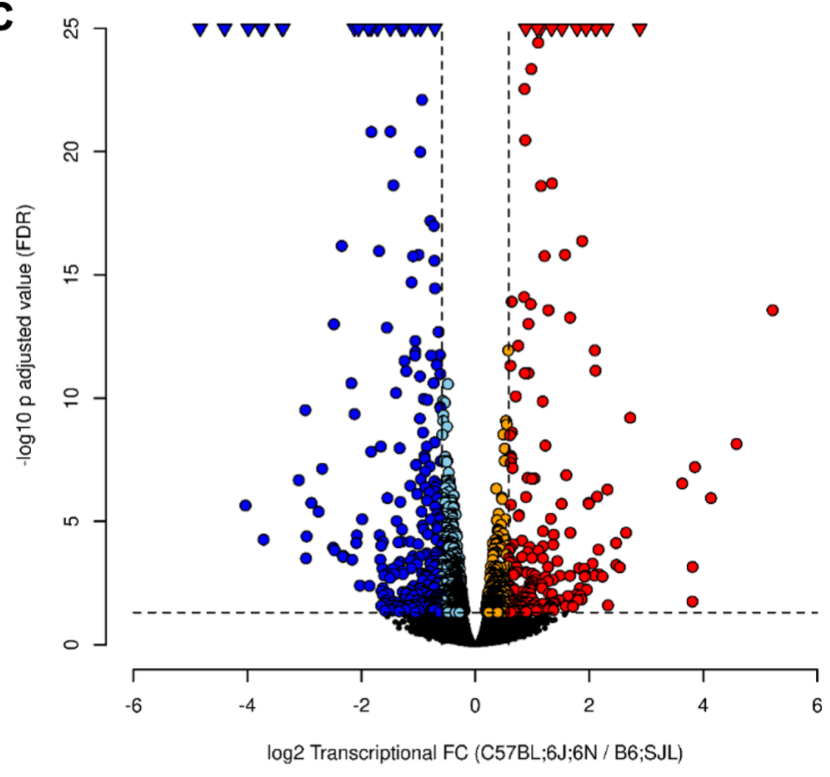

Differentially

Expressed

Genes (B, C)

- $>1.5$-fold

$0>1$-fold

- $<1$-fold

$0<1.5$-fold

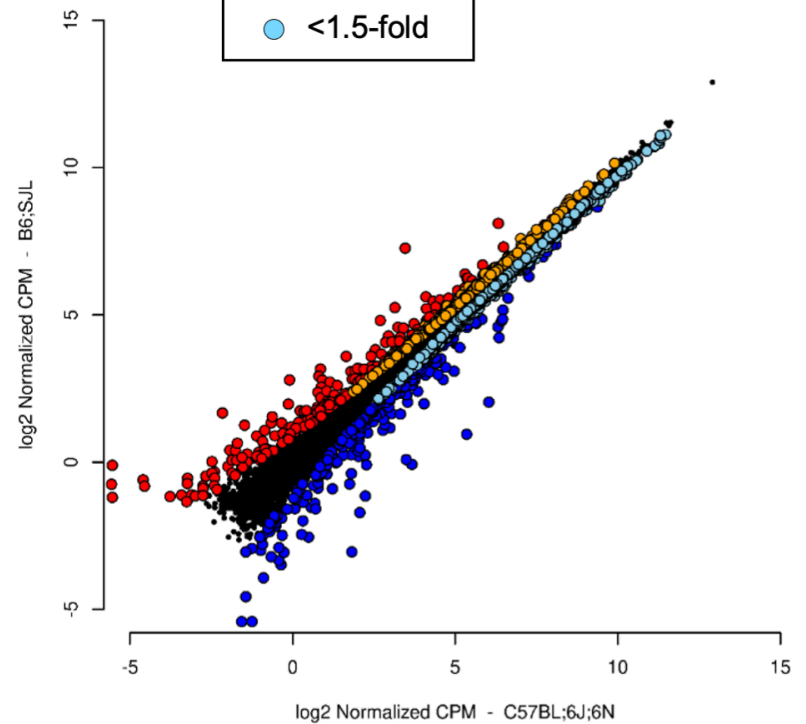

D
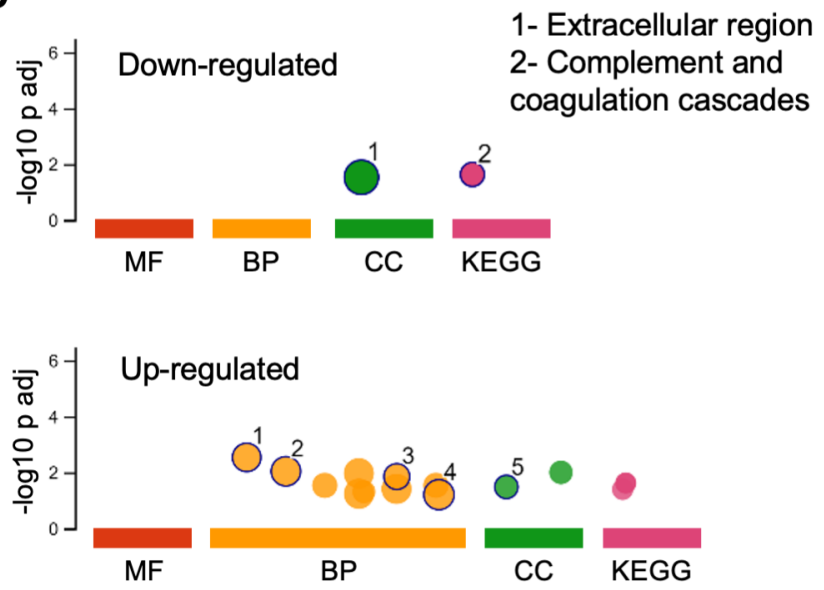

1- Immune effector process

2- Defense response to other organism

3- Response to virus

4- Response to other organism

5- Sperm flagellum

Fig. S13. Differential expression analysis performed by edgeR for the transcriptome compartment comparing WT strains. A) Principal component analysis. B) Scatter plot comparing normalized CPM expressions at the transcriptome level between genotypes. C) Volcano plot showing the relationship between FC and p-adjusted values. D) Functional enrichment analysis of differentially expressed genes performed by g:GOSt from g:Profiler. 


\section{WT (C57/BI6) versus WT (B6;SJL)}

\section{Translatome}

A

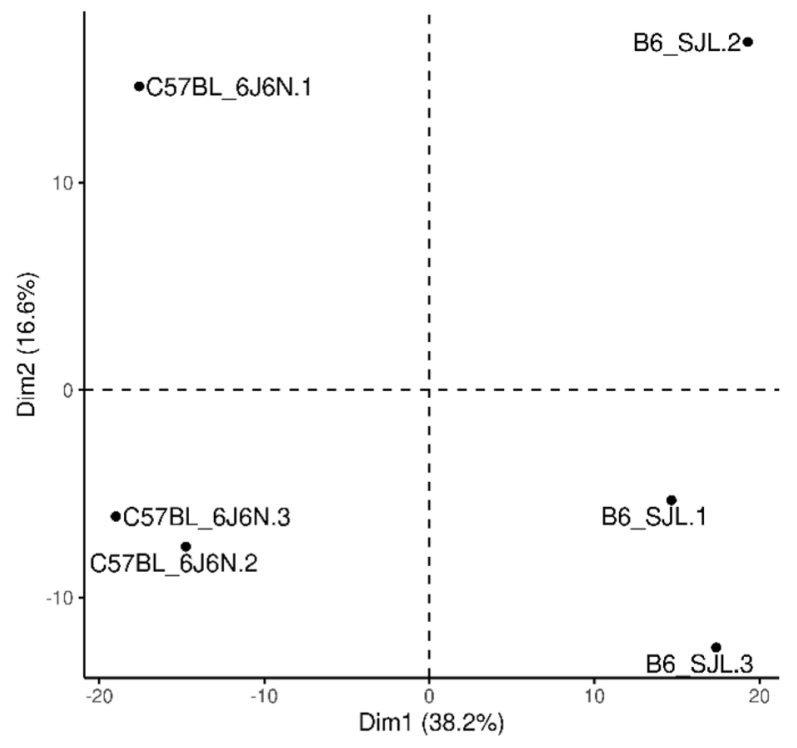

C

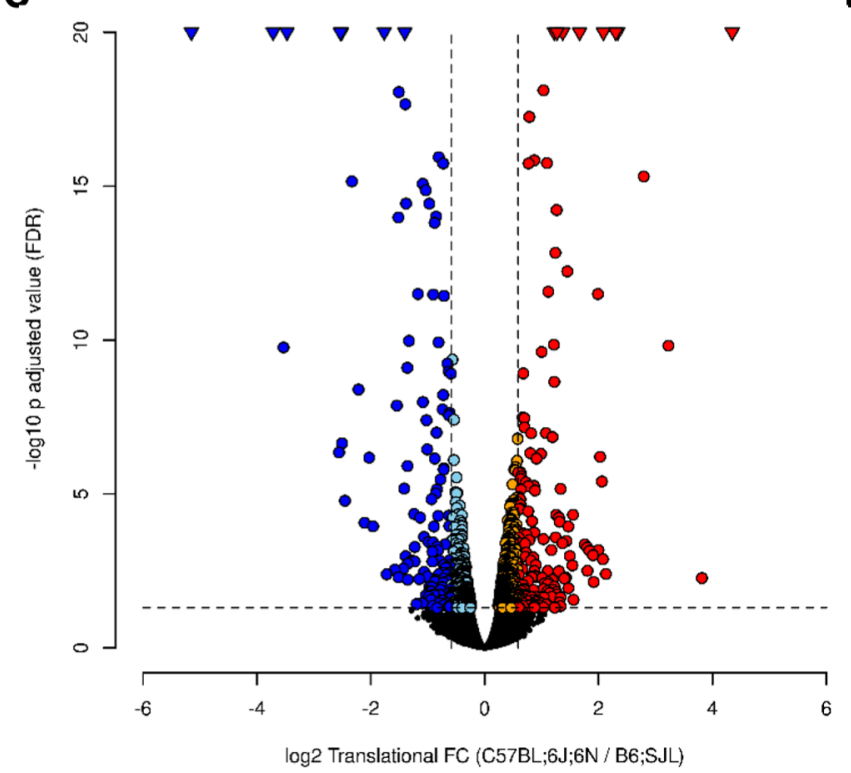

B

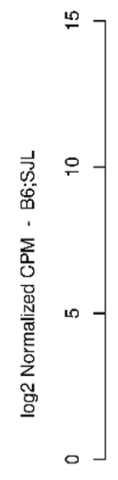

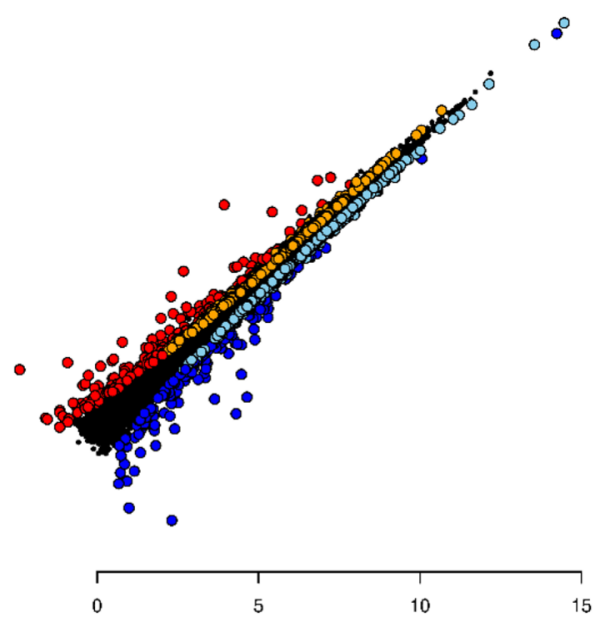

$\log 2$ Normalized CPM - C57BL;6J;6N

D

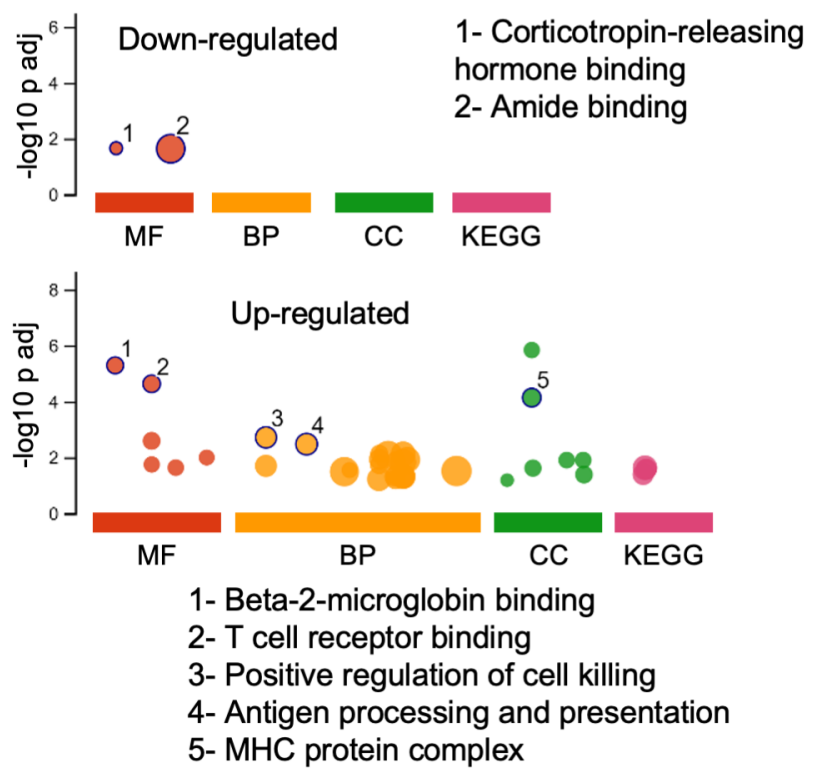

Fig. S14. Differential expression analysis performed by edgeR for the translatome compartment comparing WT strains. A) Principal component analysis. B) Scatter plot comparing normalized CPM expressions at the translatome level between genotypes. C) Volcano plot showing the relationship between FC and p-adjusted values. D) Functional enrichment analysis of DEGs performed by g:GOSt from g:Profiler. 


\section{TYROBP immune response in CVN microglia}

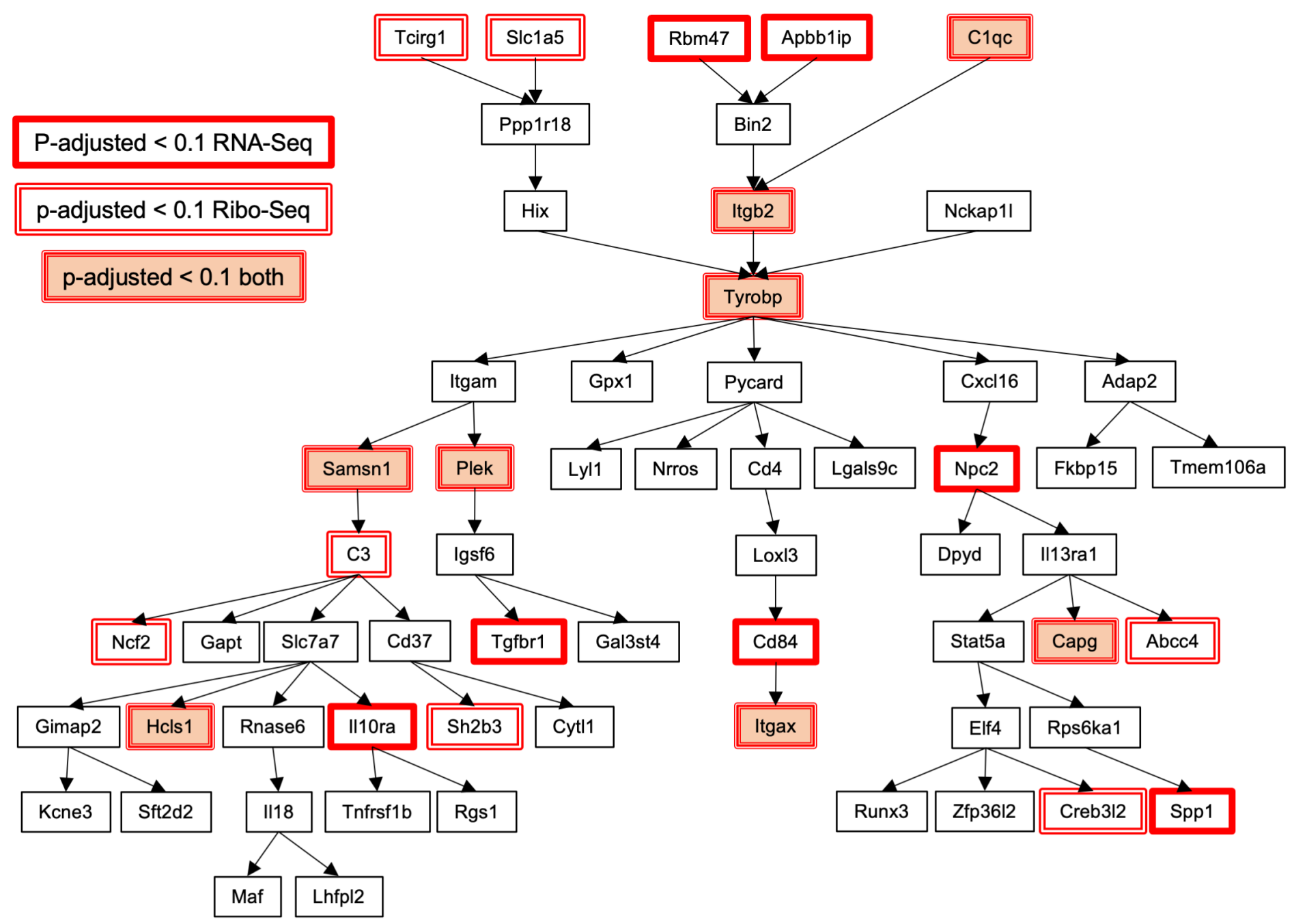

Fig. S15. Gene expression regulation of TYRO protein kinase-binding protein (TYROBP) related immune response in CVN microglial cells. Pathway with direct and indirect causal inputs upstream and downstream of TYROBP was obtained from WikiPathways, reconstructed from Zhang B. et al. Cell (2013) and Ryu JK. et al. Nat Immunol (2018). Up-regulated genes at p-adjusted value $<0.1$ for transcriptome or translatome data sets are indicated, but no significant down-regulated genes were found. 